DEMOGRAPHIC RESEARCH

VOLUME 31, ARTICLE 11, PAGES 275-318

PUBLISHED 29 JULY 2014

http://www.demographic-research.org/Volumes/Vol31/11/

DOI: 10.4054/DemRes.2014.31.11

Research Article

A method for socially evaluating the effects of
long-run demographic paths on living standards

Nick Parr

Ross Guest

(C)2014 Nick Parr and Ross Guest.

This open-access work is published under the terms of the Creative Commons Attribution NonCommercial License 2.0 Germany, which permits use, reproduction \& distribution in any medium for non-commercial purposes, provided the original author(s) and source are given credit.

See http:// creativecommons.org/licenses/by-nc/2.0/de/ 


\section{Table of Contents}

1 Introduction 276

$2 \quad$ Social valuation of demographic paths 278

$2.1 \quad$ The effect of population age structure on living standards 278

$2.2 \quad$ Valuing population trends 279

$2.3 \quad$ Comparing social values of alternative demographic paths 281

3 Simulations 283

3.1 Projections of the support ratio $L_{t} / N_{t} \quad 285$

3.1.1 Baseline series 285

3.1.2 The effect of projected mortality decline 285

3.1.3 The effects of future net immigration 287

3.1.4 The effects of future fertility 289

3.2 Social valuations of projections of the support ratio $L_{t} / N_{t} \quad 290$

3.2.1 Introduction 290

3.2.2 The effect of projected mortality change on social valuations 291

3.2.3 The effects of future migration on social valuations 293

3.2.4 The effects of future fertility on social valuations 294

3.2.5 The effect of extrapolated changes in labour force participation on 295 social valuations

3.2.6 The effect of weighting for consumption needs 297

3.2.7 The effect of diminishing returns to scale on the valuations 298

3.2.8 The effect of aversion to intergenerational inequality on social 301

$4 \quad$ Discussion and conclusion 303

5 Acknowledgements 307

$\begin{array}{ll}\text { References } & 308\end{array}$

$\begin{array}{ll}\text { Appendix A } & 314\end{array}$

$\begin{array}{ll}\text { Appendix B } & 316\end{array}$ 


\title{
A method for socially evaluating the effects of long-run demographic paths on living standards
}

\author{
Nick Parr ${ }^{1}$ \\ Ross Guest ${ }^{2}$
}

\begin{abstract}

\section{BACKGROUND}

The paper is motivated by the need for improved social evaluation of prospective demographic change in order to better inform policies that are designed to reduce the very long-run costs of population ageing and to achieve sustainable economic development.
\end{abstract}

\section{OBJECTIVE}

What is the very long-run social value of a given demographic path? What is the value of changes in mortality, immigration, fertility, and labour force participation? How important are shorter-term demographic changes relative to very long-term effects in determining the social value of the demographic path?

\section{METHODS}

A new simulation method is applied for socially evaluating demographic paths, by separating a demographic path into a stable population component and a transition path component. Sensitivity analyses are conducted with respect to demographic assumptions, labour force participation assumptions, and consumption needs by age, returns to scale, and intergenerational value judgements.

\section{RESULTS}

The application to Australia shows the considerable social cost, in terms of the loss of discounted consumption per capita, of improvements in mortality and gains from higher immigration and increased participation. The effect of fertility, however, is very sensitive to assumptions about the age-specific consumption needs of the population and social value judgements about intergenerational equity.

\footnotetext{
${ }^{1}$ Macquarie University, Australia. E-Mail: nick.parr@mq.edu.au.

${ }^{2}$ Griffith University, Australia. E-Mail: r.guest@griffith.edu.au.
} 


\section{CONCLUSIONS}

Our method socially evaluates the very long-run implications of specified constant fertility, mortality, and migration, giving consideration to both the transition path and the ultimate stable state. Mortality improvement is costly and higher immigration is beneficial. The impact of higher fertility is sensitive to assumptions about consumption needs and intergenerational equity.

\section{Introduction}

This paper proposes a method for socially evaluating the trajectories of long-run population projections. Governments in developed countries have, in recent decades, become increasingly concerned about the future population ageing that is reflected in their population projections, and which has implications for national prosperity, government budgets ${ }^{3}$, and sustainable economic development. A range of public policies have been introduced to either slow down population ageing or to ameliorate its effects on national prosperity and government budgets. Policies to slow down ageing include pro-fertility policies such as child subsidies of various kinds (McDonald 2006; Gauthier 2007; Guest and Parr 2010; Parr and Guest 2011; Guest and Parr 2013) and pro-immigration policies (Malmberg 2006). Policies to boost both supply and demand for older workers (OECD 2006) ${ }^{4}$ are designed to reduce the national economic burden of ageing. Population is also seen as a mediating factor in sustainable economic development. The Australian Government, for example, produced a Sustainable Population Strategy in 2011 (Commonwealth of Australia 2011). Such strategies, however, typically sidestep any social evaluation of the nation's prospective demographic path, and rather focus on the implications of demographic paths for the 'needs' of the population in terms of infrastructure such as water, energy, transport and communication, of government services, education, and training, and of environmental amenity.

It is the public policy attention to the economic effects of demographic change that motivates the social evaluation of alternative demographic paths proposed in this paper.

\footnotetext{
${ }^{3}$ Popular discussion of the costs of population ageing tends to conflate the national economic burden of ageing with the fiscal costs of ageing. The former refers to the effect of ageing on national consumption per capita over time, while the latter refers to the expected impact on government revenue and spending.

${ }^{4}$ The OECD is currently (mid 2011 to 2014) conducting a follow up review of its major report: Live Longer, Work Longer: A synthesis report, which surveys the policy initiatives that have been taken, and are planned to be taken, to boost the employment of older workers. http://www.oecd.org/employment/employment policiesanddata/ageingandemploymentpolicies.htm.
} 
The standard approach taken to such evaluations in the population economics literature is to embed demographic structure into an intertemporal macroeconomic model of optimal economic growth and then simulate the long-run effects of demographic change. The seminal study is Cutler et al. (1990), which has spawned a large literature ${ }^{5}$. A key feature of these models is optimising behaviour of either individual agents or a social planner. Much controversy exists in the literature about the merits of such an approach. For a comprehensive, accessible critique of representative agent models see Kirman (1992); and for a post-GFC ${ }^{6}$ critique that includes the more sophisticated version known as dynamic stochastic general equilibrium (DSGE) models see Quiggin (2012). In Cutler et al. (1990), for example, a social planner maximises a social welfare function, which is a discounted utility function ${ }^{7}$, over an infinite time horizon. Aside from any issues about the economic assumptions in their model, their method does not consider the full long-run effects of demographic change. Their population projection is truncated after a finite period of time ${ }^{8}$, beyond which the age structure remains constant at the level existing at the end point of the projected period. It therefore ignores the effect that the momentum of demographic change, created during and preceding the projection period, will have on the age structure in the very long run. In particular, any change to the age and sex composition of a population that affects its reproductive capacity will have long-run 'echo' effects on the age composition which reverberate ad infinitum (Auerbach and Kotlikoff 1987). Hence a social evaluation of alternative scenarios for fertility, mortality, and migration should consider the very long-run paths of the resultant population age structure and the terminal stable population to which the populations converge ${ }^{9}$. Auerbach and Kotlikoff $(1987,1992)$ simulate the effects of projected population age structure on a range of macroeconomic outcomes, including savings rates, wage rates, interest rates, and taxation rates, both for the terminal (longrun") stable populations and for the more immediate years of the transition towards these outcomes, but do not unify these effects within single figure summary measures of the value of these differences across the full duration of the transition. Moreover, they do not consider examples involving pairs of demographic paths which approach differing terminal stable populations.

In this paper the contribution of the method for socially evaluating long-run population projections is twofold. First, it unifies in a single measure the evaluation of

\footnotetext{
${ }^{5}$ For a recent example see Prettner (2013) and the references therein.

${ }^{6}$ Global Financial Crisis of 2008-2009.

${ }^{7}$ In Cutler et al. (1990) utility at time $t$ is a CES (constant elasticity of substitution) function of per capita consumption at time $t$. This utility for $t=0, . ., \infty$ is then discounted to time 0 and summed over the infinite horizon to give the value of social welfare.

${ }^{8}$ They use the (US) Social Security Administration Forecasts for 1990-2065.

${ }^{9}$ Here the projections of fertility, mortality, and migration eventually reach constant levels.
} 
the stable populations to which populations converge with the evaluation of the transition paths towards these asymptotes. This is done by partitioning the social value into a stable population component and a transition path component. Second, it allows the long-run momentum effects of changes in fertility, mortality, and migration over a finite period to be incorporated into the valuations ${ }^{10}$. The method also avoids the controversy over optimising behaviour by specifying an exogenous path for consumption per capita that is perturbed mechanistically by shifts in the employment to population ratio, which are in turn determined by demographic change. The approach does, however, incorporate value judgements of a 'social planner'11 - in particular, trade-offs between the welfare of generations in the present and future, which imply judgements about intergenerational equity ${ }^{12}$. Such trade-offs are implicit in any assessment of the role of population as a mediating factor in sustainable development. The model here adopts typical values of the key parameters driving the intergenerational distribution of living standards - that is, the social rate of time preference and social aversion to intergenerational inequality.

Section 2 of the paper describes this new methodology in its simplest form. More complex variants of the methodology are presented in Appendices A and B. In Section 3 the method is applied to prospective demographic paths for Australia, illustrating the sensitivity of the results to mortality, migration, and fertility parameters. Section 3.1 describes the demographic projections and the associated employment-to-population ratios, and Section 3.2 discusses the results of valuations of the differences between these demographic paths. The final section (4) concludes the paper.

\section{Social valuation of demographic paths}

\subsection{The effect of population age structure on living standards}

Living standards are defined here in material terms only, in particular as national consumption per capita. The following framework is useful for illustrating the important implications of the population age distribution for living standards:

\footnotetext{
${ }^{10}$ These momentum effects would manifest over an infinitely long time horizon.

${ }^{11}$ The 'social planner' is a theoretical concept, of course. It may also be thought of as a benevolent dictator, government, or even the enfranchised citizen.

${ }_{12}$ This literature has a long pedigree in optimal saving models, Ramsey (1928) being the seminal contribution.
} 


$$
\frac{C_{t}}{N_{t}}=\frac{C_{t}}{Y_{t}} \frac{Y_{t}}{L_{t}} \frac{L_{t}}{N_{t}}
$$

The symbols in this identity refer to the following national aggregates: $C_{t}$ is consumption of goods and services at time $t, N_{t}$ is the effective number of consumers (either total population or a needs-weighted population e.g. as defined by Cutler et al. 1990 or Guest and McDonald 2001), $Y_{t}$ is output of goods and services (gross domestic product, GDP), and $L_{t}$ is employment (for example, total hours worked). The ratio $C_{t} / N_{t}$ is consumption per effective consumer, $C_{t} / Y_{t}$ is the consumption share of GDP, $Y_{t} / L_{t}$ is average labour productivity, and $L_{t} / N_{t}$ is the employment to population ratio or support ratio $^{13}$.

Equation (1) can be re-expressed using age-specific components:

$$
\frac{C_{t}}{N_{t}}=\frac{C_{t}}{Y_{t}} \frac{Y_{t}}{L_{t}} \sum_{x} H_{x, t} \frac{E_{x, t}}{N_{x, t}} \frac{N_{x, t}}{N_{t}}
$$

where $H_{x, t}$ denotes hours worked per employed person in age and sex group $x$ at time $t$, and hence $L_{x, t}=\sum_{x} H_{x, t} E_{x, t}$ where $E_{x, t}$ is the number of employed persons in age and sex group $x$, and $N_{x, t}$ is population in age and sex group $x$. In (2) the population age structure affects living standards through the age-specific variation in $H_{x, t}$ and $E_{x, t} / N_{x, t}$.

\subsection{Valuing population trends}

Assumptions can be made about the way in which demographic changes affect $C_{t} / Y_{t}$ and $Y_{t} / L_{t}$ : see Cutler et al. (1990), and for a more recent empirical analysis for OECD countries using a similar framework to that in (1) see Guest (2007). This framework, however, requires a range of assumptions about the economic structure and behaviour of consumers and firms, which are deliberately avoided in this paper. Here the aim is to isolate the role of $L_{t} / N_{t}$, which is achieved through two simplifying assumptions. First, the simplest form of economy is adopted: an economy with no net exports and no investment, implying $C_{t}=Y_{t}$. Second, output $(Y)$ is determined by a simple production function (without capital): ${ }^{14}$

${ }^{13}$ For discussion of the economic implications of (zero migration) stable age distributions see Arthur and McNicoll (1978) and Lee (1980).

${ }^{14} \mathrm{We}$ are grateful to an anonymous referee for pointing out the need to specify a production function in which labour-augmenting technical progress is constant, in order to validate other simplifications of the model. 
Parr \& Guest: A method for socially evaluating the effects of long run demographic paths on living standards

$$
Y_{t}=A_{t} L_{t}^{\alpha}
$$

where $A_{t}=\mathrm{A}_{0}\left(1+\mathrm{g}_{\mathrm{A}}\right)^{\mathrm{t}}$ is a labour-augmenting technology variable growing at a constant rate $g_{A}$ which is independent of the age composition of the population, and $\alpha$ is the returns-to-scale parameter ${ }^{15}$.

Hence the path of living standards for future values of $t$ can be written (substituting (3) into (1) and simplifying):

$$
\frac{C_{t}}{N_{t}}=\frac{C_{0}}{Y_{0}}\left(1+g_{A}\right)^{t} \frac{L_{t}^{\alpha}}{N_{t}}
$$

Given that $L_{t}$ and $N_{t}$ are both exogenous, given by demographic data, the path of living standards is also exogenous. Alternative paths of living standards can be evaluated by specifying an objective function:

$$
V=\sum_{t=0}^{\infty} f\left(\frac{C_{t}}{N_{t}}\right)(1+\rho)^{-t}
$$

where $\rho$ is a social discount rate (discussed below). The function $f\left(\frac{C_{t}}{N_{t}}\right)$ captures the social weighting of $f\left(\frac{C_{t}}{N_{t}}\right)$ and can take various functional forms. Here we take the simplest possible form: $f\left(\frac{C_{t}}{N_{t}}\right)=\left(\frac{C_{t}}{N_{t}}\right)$. Appendix A discusses a common alternative functional form in the literature and introduces a parameter that captures the social aversion to intertemporal inequality in $\left(\frac{C_{t}}{N_{t}}\right)$, and simulations are reported for non-zero values. In the simplest case where this parameter is zero the objective function is:

$$
V=\left(\frac{C_{0}}{Y_{0}}\right)\left[\sum_{t=0}^{\infty}\left(\frac{1+g_{A}}{1+\rho}\right)^{t}\left(\frac{L_{t}^{\alpha}}{N_{t}}\right)\right]
$$

\footnotetext{
${ }^{15}$ For simplicity in subsequent equations we drop the constant scalar $\mathrm{A}_{0}$.
} 
From (6), the social evaluation of alternative paths for living standards depends on the path of $\frac{L_{t}^{\alpha}}{N_{t}}$ and the factor $\left(\frac{1+g_{A}}{1+\rho}\right)^{t}$. The choice of a value for $\rho$ depends on judgements about the social value of the consumption of present relative to future generations (Samuelson 1958). Some authors have argued that any value of $\rho$ greater than zero is unethical since it implies that the welfare of future generations is less important simply because they live in the future rather than the present (Ramsey 1928; Pigou 1932). Others favour a positive value of $\rho$ by appealing to uncertainty about the future of the world (Stern 2007) and/or to the observed saving rates of individuals (Weitzman 2007) ${ }^{16}$. Typical values for $\rho$ found in the literature range from 0.001 to 0.02 (as surveyed in Scarborough 2011). The value adopted here is $0.0175^{17}$.

The purpose of the simulations, discussed below, is to assess the role of demographic assumptions in generating $\frac{L_{t}^{\alpha}}{N_{t}}$ and hence $V$, and the sensitivity of these results to alternative values of key parameters $g_{A}, \rho$ and a parameter that captures social aversion to inequality in intertemporal consumption (discussed in Appendix A). Appendix B shows that the valuation function (6) is readily extended to accommodate linear effects of the projected proportionate age distributions of the population on $\left(Y_{t} / L_{t}\right)$ or $\left(C_{t} / Y_{t}\right)$.

\subsection{Comparing social values of alternative demographic paths}

The method we propose applies to projections in which $L_{t}^{\alpha} / N_{t}$ converges in the very long run to a constant value. The focus in this paper is on the subclass of population projections in which age-specific fertility, age-specific mortality rates, and the annual number and age distribution of immigration all eventually reach constant levels. Under these conditions the population asymptotically approaches a stable age distribution and, if fertility is below replacement level and net immigration is inwards, a stationary population (Pollard 1973; Espenshade et al. 1982). Attention is further restricted to projections where the age-specific labour force participation rates $\left(H_{x, t} E_{x, t} / N_{x, t}\right.$ in (2)) also eventually become constant. Thus the valuations are of the very long-run implications of finite changes to population age structure and labour force participation.

${ }^{16}$ Individuals tend to be myopic in their own life planning in well-known ways that indicate a rate of time preference. As an example of a form of myopia in an intergenerational context, a mother is likely to care more about her children than her grandchildren and even less about her great grandchildren.

${ }^{17}$ This value is towards the top of the plausible range but must be greater than $g$ to ensure a finite value of $V$. 
Parr \& Guest: A method for socially evaluating the effects of long run demographic paths on living standards

$C_{t} / N_{t}$ can be decomposed as follows:

$$
\left(\frac{C_{t}}{N_{t}}\right)=\left(\frac{C_{s}}{N_{s}}\right)+\left[\left(\frac{C_{t}}{N_{t}}\right)-\left(\frac{C_{s}}{N_{s}}\right)\right]
$$

where $\left(C_{s} / N_{s}\right)$ is a constant which equals the living standard for the asymptotic (henceforth "terminal") stable age distribution of the projection series. Substituting from (7) into (6):

$$
V=\left(\frac{C_{0}}{Y_{0}}\right)\left[\sum_{t=0}^{\infty}\left(\frac{1+g_{A}}{1+\rho}\right)^{t}\left(\frac{L_{s}^{\alpha}}{N_{s}}\right)+\sum_{t=0}^{\infty}\left(\frac{1+g_{A}}{1+\rho}\right)^{t}\left[\left(\frac{L_{t}^{\alpha}}{N_{t}}\right)-\left(\frac{L_{s}^{\alpha}}{N_{s}}\right)\right]\right]
$$

In (8) the value of the series is expressed as two components: the first is the value of the terminal stable population and the second a value of the difference between the projection series and the terminal stable population. We term the first of these the "(terminal) stable population component" and the second component the "transition path component". Hence the difference in social values of any two demographic projections, A and B, can be expressed as the sum of a "difference in stable population components" plus a "difference in the transition path components".

$$
\begin{aligned}
V(A)-V(B)=\left(\frac{C_{0}}{Y_{0}}\right)[ & \sum_{t=0}^{\infty}\left(\frac{1+g_{A}}{1+\rho}\right)^{t}\left(\left(\frac{L_{s, A}^{\alpha}}{N_{s, A}}\right)-\left(\frac{L_{s, B}^{\alpha}}{N_{s, B}}\right)\right)+ \\
& \left.\sum_{t=0}^{\infty}\left(\frac{1+g_{A}}{1+\rho}\right)^{t}\left(\left[\left(\frac{L_{t, A}^{\alpha}}{N_{t, A}}\right)-\left(\frac{L_{s, A}^{\alpha}}{N_{s, A}}\right)\right]-\left[\left(\frac{L_{t, B}^{\alpha}}{N_{t, B}}\right)-\left(\frac{L_{s, B}^{\alpha}}{N_{s, B}}\right)\right]\right)\right]
\end{aligned}
$$

$V(A)-V(B)$ is finite when $\rho>g_{A}$, in which case the value of the stable population component in (7) is simply calculated as the sum of a geometric series ${ }^{18}$. The elements of the transition path component can be calculated for all values of $t$ for which the projection has been calculated. The residual element may be estimated

\footnotetext{
${ }^{18}$ We consider the case of discrete (annual) population change as opposed to continuous change. Under continuous change the estimation of the transition path component would be problematic for real (and hence mathematically irregular) base population scenarios.
} 
through model-based imputation ${ }^{19}$. Equations (8) and (9) may be modified to incorporate linear effects of the projected proportionate age distributions of the population on $\left(Y_{t} / L_{t}\right),\left(C_{t} / Y_{t}\right)$ or $\left(C_{t} / L_{t}\right)$ (see Appendix B).

Cumulative contributions to the differences in value for various future intervals of time, both in absolute terms and in proportionate terms, may also be calculated. The contribution to the difference in value for the first $T$ years of the projection is:

$$
V_{t=0}^{T}(A)-V_{t=0}^{T}(B)=\left(\frac{C_{0}}{Y_{0}}\right)\left(\sum_{t=0}^{T}\left(\frac{1+g_{A}}{1+\rho}\right)^{t}\left[\left(\frac{L_{t, A}^{\alpha}}{N_{t, A}}\right)-\left(\frac{L_{t, B}^{\alpha}}{N_{t, B}}\right)\right]\right)
$$

This can be converted into proportionate terms by dividing by the (total) value of the difference from (9). Such figures can provide an indication of the inadequacy which valuations considering only trends over these finite periods of time would have.

\section{Simulations}

The simulations give social valuations of differences in demographic projections for Australia. A baseline series is compared with a range of variants, each of which differs from the baseline in only one of the assumptions for future mortality, migration, and fertility ${ }^{20}$. The valuations use a rate of labour-augmenting productivity growth $\left(g_{A}\right)$ of $1.5 \%$ per annum, a returns to scale parameter of $1.0,{ }^{21}$ and a social discount rate of $1.75 \%$ per annum. As extensions, consumption units per effective person are calculated by weighting the consumption needs of the population by age, following, firstly, Cutler et al. (1990) and, secondly, weights proposed for Australia by Guest and McDonald (2001). Under Cutler et al.'s weights each person aged 0-19 years is given a consumption-needs weight of 0.72 and each person above age 65 is given a weight of 1.27. The weights proposed by Guest and McDonald (2001) are for narrower age bands.

\footnotetext{
${ }^{19}$ The mathematical function used for this must tend to zero as time tends to infinity. The value of this element is estimated through either summation of a series or integration of a curve.

${ }^{20}$ Theoretically the valuations will be affected also by the proportional age structure of the start population, and hence by past fertility, mortality, and migration. We omit to illustrate the sensitivity of results to this distribution.

${ }^{21}$ Constant returns to scale is adopted here in order to avoid the deflating of future labour implicit in the term $L^{\alpha}$ with $\alpha<1$. This could have been avoided by introducing capital into the production function (3), which would have removed the $\alpha$ exponent from $L$ without requiring constant returns to scale. However we wanted to avoid an analysis of the impact of demographic change on the capital-labour ratio, instead focusing on the impact on the support ratio.
} 
The consumption weight is lowest for $0-15$ year olds (0.68) and highest for the 75 and over age group (1.19). There are small undulations in the values between these age ranges $^{22}$. We also consider the effect of returns-to-scale parameter $(\alpha)$ of 0.95 . A further extension is to incorporate a parameter for aversion to intergenerational inequality of living standards (Appendix A). All projections use the 2011 estimated resident population of Australia as the base population.

The baseline series illustrates the effects of mortality improving to 2050, as projected by $\mathrm{Li}$ (2013) using the Poison Common Factor variant of the Lee-Carter model, and remaining constant thereafter ${ }^{23}$. In addition, the levels and age distributions of both fertility (TFR $=1.9)$ and net international migration $(180,000$ per annum) are assumed to remain constant at roughly the levels for recent years (ABS 2012a, 2013a). The age- and sex-specific labour force participation rates are assumed to remain constant at the 2011 levels (ABS, 2012b). Table 1 summarises the assumptions for the baseline series and the differences between the variant series and the baseline. Section 3.1 describes the projected trajectories for hours worked per head of population $\left(L_{t} / N_{t}\right)$ (Section 3.1) followed by the projected social valuations (Section 3.2).

\footnotetext{
${ }^{22}$ Data which allow consumption weights to be developed for a range of countries (excluding Australia) are available from the National Transfer Accounts project (http://www.ntaccounts.org).

${ }^{23}$ The plausibility of an upper limit to life expectancy has been debated in the literature (Oeppen and Vaupel 2002; Carnes et al. 2003). The method we propose is only estimable if all the input parameters, including mortality rates, eventually converge to a limit. The evaluation of the effect of projected mortality change over a finite period (in this case 2011-2050) can be estimated, conditional on the assumed path of mortality following the end of that period (and on paths for other model parameters). Constant mortality at the level of the end point of the projected change appears to us the most logical of the possible choices.
} 
Table 1: $\quad$ Specification of the baseline and variant series

\begin{tabular}{ll}
\hline Series & Assumptions $^{\text {a }}$ \\
\hline Baseline & $\begin{array}{l}\text { Life expectancy increases to } 87.6 \text { for males and } 90.7 \text { for females by } 2050 \\
\text { using the projection of Li (2013), and is constant thereafter. } \\
\text { Net migration constant at } 180,000 \text { per annum. } \\
\\
\text { Total Fertility Rate constant at } 1.9 .\end{array}$ \\
A & Mortality constant at 2011 levels \\
B & Net migration constant at 90,000 from 2011 onwards. \\
C & Net migration constant at 270,000 from 2011 onwards \\
D & Net migration constant at zero from 2011 onwards \\
E & Total Fertility Rate constant at 1.7 from 2011 onwards \\
F & Total Fertility Rate constant at 2.1 from 2011 onwards \\
\hline
\end{tabular}

Note: a. For the variant series all assumptions other than the tabulated are as per the baseline series.

\subsection{Projections of the support ratio $L_{t} / N_{t}$}

\subsubsection{Baseline series}

Under the baseline series the population of Australia is projected to increase with a decreasing growth rate, and to age significantly ${ }^{24}$. The hours-worked-to-population ratio $\left(L_{t} / N_{t}\right)$ is projected to decrease at a progressively more gradual rate, from 16.6 in 2011 to 15.0 in $2050,14.7$ in $2100,14.5$ in 2200 , and 14.0 in the terminal stationary population (Figure 1). The population is projected to increase from 22.3 million in 2011 to 35.6 million by $2050,50.1$ million by $2100,73.0$ million by 2200 , and towards 153.4 million in its terminal stationary state.

\subsubsection{The effect of projected mortality decline}

Under series A, which differs from the baseline series only in its assumption of constant mortality, the projected reduction in $L_{t} / N_{t}$ is smaller than under the baseline, reaching

\footnotetext{
${ }^{24}$ The population increases under the baseline projection even though fertility is below replacement. This is because net immigration is positive. In the more immediate future positive net immigration adds to positive natural increase. Over the longer term positive net immigration continues to more than offset negative natural increase, with the sum of the two converging to zero.
} 
15.4 for $2050,15.3$ for 2100 , and 15.0 in the terminal stationary population (Figure 1). The difference from the baseline is due to the lower projected percentages of the population in the low-participation-rate-older-ages under the constant mortality (series A) scenario, compared to the baseline scenario with its projected mortality improvement. Comparison of this constant mortality variant series with the baseline shows that only $26.4 \%$ of the projected reduction in $L_{t} / N_{t}$ by $2050,31.1 \%$ of the projected reduction to 2100 , and $37.4 \%$ of the projected change to the terminal stationary population are attributable to the projected improvements in mortality. Even though in the baseline scenario mortality improvement ceases abruptly in 2050 , the widening gap in $L_{t} / N_{t}$ post-2050 shows there is a significant longer-term flow-on effect of the projected improvement in mortality between 2011 and 2050 over the post-2050 period, which illustrates the limitation in truncating the projection period too early.

Under constant mortality the projected population growth is less than under the baseline: the population is projected to reach 34.0 million in 2050, 66.9 million in 2200 , and 120.1 million in the terminal stationary population.

Figure 1: Effects of varying mortality on projected support ratio $\left(\mathrm{L}_{\mathrm{t}} / \mathbf{N}_{\mathrm{t}}\right)$ : Baseline forecast of mortality improvement vs constant mortality at 2011 level

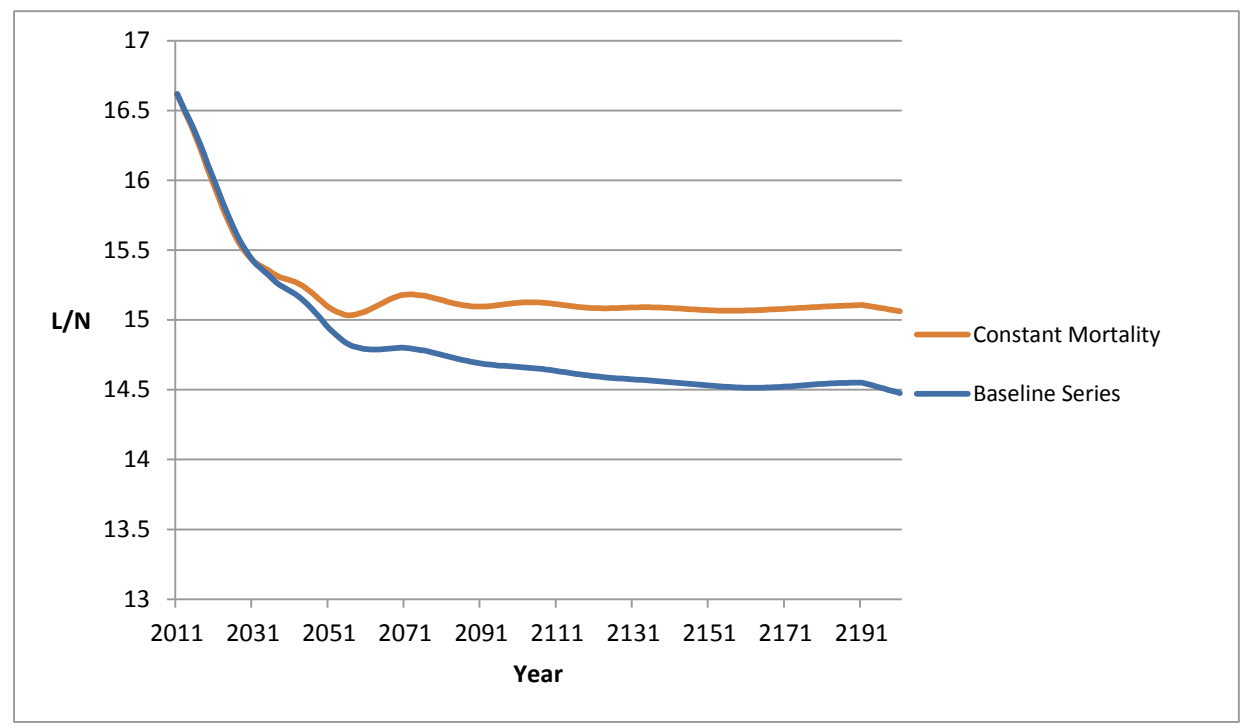




\subsubsection{The effects of future net immigration}

The contrasts between series B (a reduction in net migration to 90,000) and series C (an increase to 270,000) from the baseline show that in the short and medium term the higher the level of immigration the higher the $L_{t} / N_{t}$ (Figure 2) (Bloom et al. 2010; McDonald and Temple 2010). There are, however, diminishing returns to increasing net migration: the effects on this ratio of an increase in net migration from 180,000 to 270,000 per annum are slightly smaller than those of an increase from 90,000 to 180,000 . In the very long run the effects of higher or lower net migration approach zero $^{25,26,27}$. Under all plausible scenarios, immigration does not arrest the decline in $L_{t} / N_{t}$ due to population ageing ${ }^{28}$.

The effect of higher net immigration on $L_{t} / N_{t}$ increases gradually until about $2054^{29}$, and decreases gradually thereafter. The terminal stationary populations for all the series with non-zero migration are identical in their proportionate age structures and hence hours-worked-to-population ratios.

Under series D (zero net migration) the reduction in $L_{t} / N_{t}$ in the absence of net migration is steeper than under all three positive net migration scenarios, falling to 14.1 in 2050 and 14.0 in 2100 . The difference from the baseline series rises to a maximum in

\footnotetext{
${ }^{25}$ The equality of the proportionate age distributions of the terminal stationary populations, and hence of support ratios, is the product of the assumed equal proportionate age distributions of these migrant intakes. If the higher and lower variants differed from the baseline in the proportionate age distributions for net migration then differing age structures for the terminal stationary populations would result (Pollard 1973).

${ }^{26}$ For simplicity it is assumed the proportionate age and sex distribution of net migration is invariant to its total level. The recent historical variation in net immigration in Australia has primarily been due to variation in immigration, as opposed to emigration. The age distributions of immigrants and emigrants differ, with the former being slightly younger on average than the latter (ABS 2012c). Hence in practice a higher level of net migration would be expected to have a somewhat younger profile and a lower level a somewhat older profile.

${ }^{27}$ The model assumes labour force participation rates and labour productivity are invariant to the level of immigration. In contrast to most other OECD countries, in Australia the unemployment rate for the migrant population differs little from that for the native-born. The labour force participation rate for migrants is slightly below that for the Australia-born. The percentage of the employed working part-time is lower for the overseas-born than for the Australia-born, particularly for females (Massey and Parr 2012; DIAC 2013). There may also be positive or negative 'spillover effects' of the level of immigration on the employment levels of the native-born. However, the international literature suggests such effects are generally minor (Kerr and Kerr 2011). The economic outcomes of the children of immigrants also differ from those of the nativeborn (DIAC 2013).

${ }^{28}$ Net migration of well over 800,000 per annum would be needed to maintain $L_{t} / N_{t}$ at around its 2011 level. Even with such levels of migration the ratio would decline from around 2045 onwards.

${ }^{29}$ The maximum difference between the 270,000 per annum net migration projection and the 180,000 per annum baseline projection is 0.32 hours per week per person $(2.1 \%$ of the value of the baseline series) and occurs in 2052. The maximum difference between the 90,000 per annum net migration projection and the 180,000 per annum baseline projection is 0.43 hours per week per person $(2.1 \%$ of the value of the baseline series) and occurs in 2053.
} 
2055 and thereafter decreases. Under zero migration the terminal stable age distribution differs from that for positive net immigration, with $L_{t} / N_{t}$ (13.8 hours worked per week per capita) being appreciably lower.

The projected population under the high migration (270,000 per annum) rises to 40.7 million by $2050,100.7$ million by 2200 , and 230.1 million in the terminal stationary state.

Figure 2: $\quad$ Effects of varying migration on projected support ratio $(\mathrm{Lt} / \mathrm{Nt})$ : Baseline (180,000 pa) vs low (90,000pa), high (270,000pa) and zero

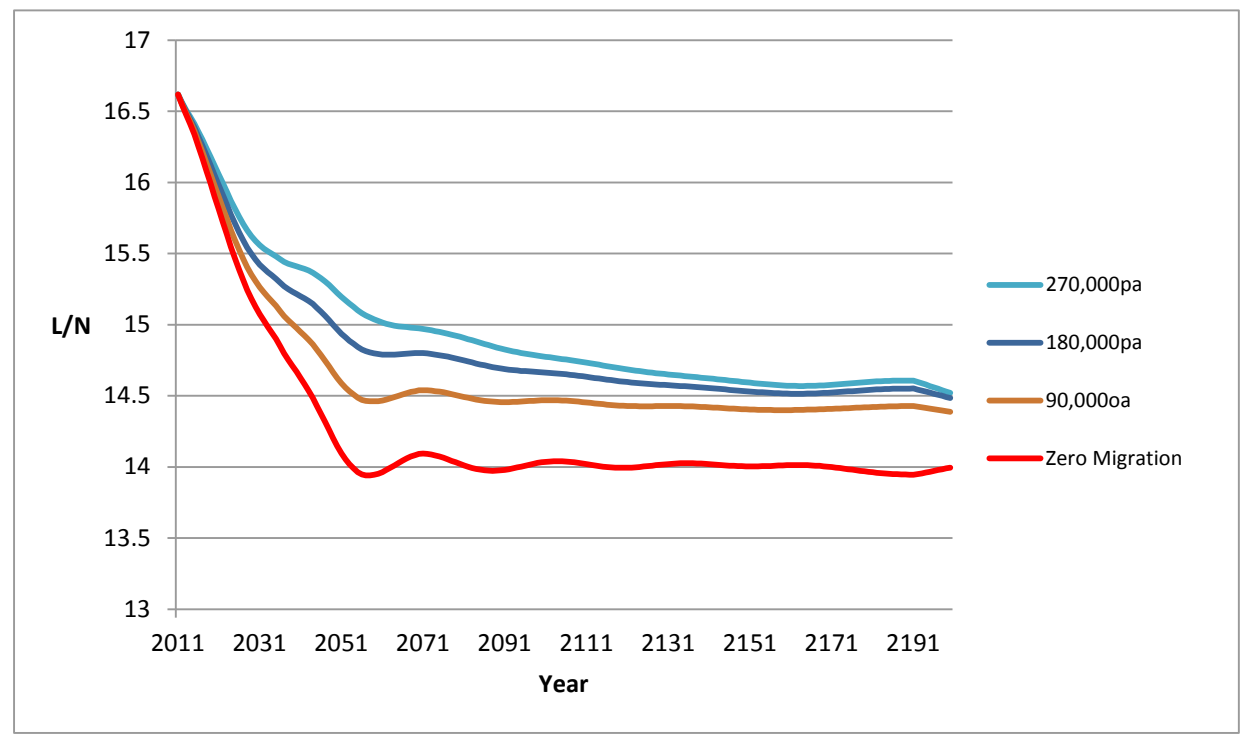

Under the low migration variant $(90,000$ per annum) the projected population growth is considerably less: the population reaches 30.5 million in 2050, 45.4 million in 2200 , and 76.7 million in the terminal stationary state. Under zero migration the projected population rises gradually to a peak of 25.4 million in 2051 before declining gradually to 17.7 million by 2200 and towards zero asymptotically. The sizes of the projected terminal stationary populations are in direct proportion to the size of the migrant intakes (Pollard, 1973; Espenshade et al. 1982; Schmertmann 1992, 2012). 


\subsubsection{The effects of future fertility}

Under the lower fertility $(\mathrm{TFR}=1.7)$ projection $L_{t} / N_{t}$ is significantly higher in the short term than under the baseline, whilst under the higher fertility projection $(\mathrm{TFR}=2.1$ ) $L_{t} / N_{t}$ is significantly lower (Figure 3 ). The differences in $L_{t} / N_{t}$ between the baseline and variant projections increase until they reach their maximum values around 2031, after which point they reduce as the effect of the fertility difference affects the sizes of above-average hours worked per person (i.e., over age 20) age groups as well as the below-average hours worked per person age groups below age $20^{30}$. By around 2070 the differences in $L t / N t$ between the projections with differing fertility levels are small. This illustrates the general result that the long-run effects on $L_{t} / N_{t}$ of alternative fertility scenarios are small (Weil 1999). The $L t / N t$ for the terminal stable population under the lower fertility scenario $(\mathrm{TFR}=1.7)(14.1 \mathrm{Lt} / \mathrm{Nt})$ is slightly higher than for the baseline scenario $(14.0)$, whilst that for the higher fertility scenario (TFR $=2.1$ ) is slightly lower $(13.9 \text { hours per week })^{31,32}$. These results reflect a more general pattern of the $L t / N t$ for the terminal stable populations decreasing as fertility increases across the belowreplacement range of values for fertility ${ }^{33,34}$. In contrast to the above scenarios with positive net immigration, when migration is zero a TFR of around 2.35 produces the highest value of $L / N$ in the terminal stationary population, with the projected mortality for 2050 .

The projected population growth under the low fertility $(\mathrm{TFR}=1.7)$ scenario is slightly less in the short-to-medium run compared to under the baseline, but very considerably less in the very long run. By 2050 the population is projected to be 33.9 million, just 1.7 million less than the baseline. However, by 2200 it is projected to be 54.3 million ( 18.7 million or $25.6 \%$ less) and the terminal stationary population of 67.5 million is less than half (only $44.0 \%$ ) of that for the baseline series ${ }^{30}$. Under the high fertility scenario $(\mathrm{TFR}=2.1)$ the population is projected to grow to 37.4 million by

\footnotetext{
${ }^{30}$ The maximum difference in the $L t / N t$ between the lower fertility $(\mathrm{TFR}=1.7)$ scenario and the baseline scenario is 0.33 hours per week per capita, whilst that between the higher fertility scenario and the baseline is 0.31 hours per week per capita. Both maxima are reached in 2031.

${ }^{31}$ Under a TFR $=0$ assumption the $L t / N t$ in the terminal stable population is 15.65 . With decreasing fertility (below replacement level) the proportion of the terminal stationary population who are former immigrants increases and as fertility approaches zero the $L t / N t$ approaches that of the surviving immigrant population.

${ }^{32}$ In age distribution of the terminal stable population under a TFR of 2.1 numbers decrease monotonically with increasing age, in contrast to patterns of increasing numbers up to a maximum at age 49 with a TFR of 1.9 and a maximum at age 52 with a TFR of 1.7 .

${ }^{33}$ See Schmertmann (1992) for explanation of the variation by the fertility level in the age distributions of stationary populations with constant immigration.

${ }^{34}$ It should be noted that the value of hours worked per person in the terminal stable population increases between replacement level fertility to a local maximum corresponding to a TFR of 2.35.
} 
2050 and to 99.3 million by 2200 . Under this slightly above-replacement level of fertility the population would continue to increase indefinitely at a very gradual rate.

Figure 3: Effects of varying fertility on projected support ratio $\left(\mathrm{L}_{t} / \mathbf{N}_{t}\right)$ : Baseline $(\mathrm{TFR}=1.9)$ vs $\mathrm{TFR}=1.7$ and $\mathrm{TFR}=\mathbf{2 . 1}$

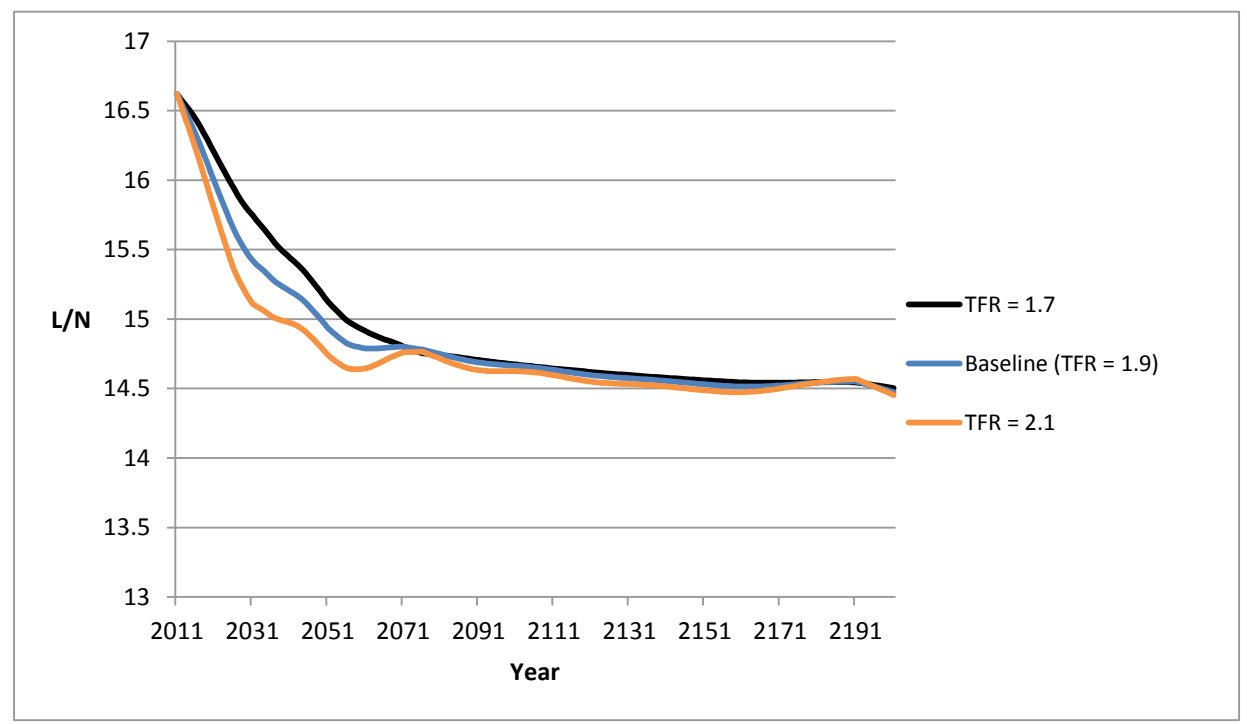

\subsection{Social valuations of projections of the support ratio $L_{t} / N_{t}$}

\subsubsection{Introduction}

The differences in social value between the variant series and the baseline series are calculated using (9). The "Terminal Stable Population" and "Transition Path" components of this difference are also given (9). The differences in social value are also expressed as percentages of the social value of the baseline projection and as a percentage of the 2011 social value of $L_{t} / N_{t}$. Table 2 summarises the results. We then illustrate the changes to the effects of future mortality, migration, and fertility under an alternative trajectory for labour force participation (Table 3), under two different weightings of the population for consumption needs (Table 4) and diminishing returns to scale (Table 5). Finally, the effects of introducing a degree of aversion to intergenerational inequality are considered (Table 6). 
Table 2: Differences in components of social value and total social value in units between variant series and baseline series with constant labour force participation rates expressed on a per capita basis: Australia 2011 onwards

\begin{tabular}{|c|c|c|c|c|c|}
\hline \multirow[t]{2}{*}{ Variant Series } & \multicolumn{3}{|c|}{ Difference from Baseline Series $^{\mathrm{a}, \mathrm{b}}$} & \multicolumn{2}{|c|}{$\begin{array}{c}\text { Modulus of Difference in } \\
\text { Total Value }^{a}\end{array}$} \\
\hline & $\begin{array}{c}\text { Stable } \\
\text { Population } \\
\text { Component }\end{array}$ & $\begin{array}{c}\text { Transition } \\
\text { Path } \\
\text { Component }\end{array}$ & $\begin{array}{c}\text { Total Social } \\
\text { Value }\end{array}$ & $\begin{array}{c}\text { As \% of } \\
\text { Value of } \\
\text { Baseline } \\
\text { Series }^{c}\end{array}$ & $\begin{array}{c}\text { As } \% \text { of } \\
\text { Social Value } \\
\text { in } 2011^{d}\end{array}$ \\
\hline A (Constant Mortality) & 409.5 & -92.1 & 317.4 & 5.1 & 1910.0 \\
\hline $\begin{array}{l}\text { B }(\text { Net Migration }= \\
90,000)\end{array}$ & 0.0 & -28.0 & -28.0 & 0.5 & 168.4 \\
\hline $\begin{array}{l}\text { C (Net Migration }= \\
270,000)\end{array}$ & 0.0 & 16.5 & 16.5 & 0.3 & 99.1 \\
\hline $\mathrm{D}($ Net Migration $=0)$ & -74.2 & -79.3 & -153.5 & 2.6 & 923.8 \\
\hline$E(T F R=1.7)$ & 54.9 & -7.9 & 47.0 & 0.8 & 282.9 \\
\hline $\mathrm{F}(\mathrm{TFR}=2.1)$ & -27.1 & -6.5 & -33.7 & 0.6 & 202.7 \\
\hline
\end{tabular}

Notes: a. Using $g_{A}=1.5 \%$ p.a., $\rho=1.75 \%$ p.a., $\alpha=1$, and $\beta=0$.

b. Expressed as a multiple of the 2011 consumption value of one hour worked per week per capita

c. Value of baseline series $=5845.5$ times the consumption value of one hour worked per week per capita in 2011 .

d. As multiple of consumption value of $2011 \mathrm{~L} / \mathrm{N}$ (16.6 hours worked per week per capita).

\subsubsection{The effect of projected mortality change on social valuations}

In the constant mortality variant series (series A), the total social value is $5.1 \%$ higher than in the baseline series. This represents the $\operatorname{cost}^{35}$ of the projected improvements in mortality to 2050 under the baseline series and is primarily due to the greater value of the terminal stable population under the higher mortality (constant) scenario (column 2). The (negative) difference in transition path components reflects the differences between the values of the constant mortality series (A) and the value for its terminal stable population being smaller than the equivalent differences for the baseline series. The $5.1 \%$ increase in social value is equivalent to 317.4 times the consumption value of

${ }^{35}$ Henceforth we refer to negative differences in values as "cost" and positive differences as "benefits". It should be noted these "costs" and "benefits" are based only on differences in support ratios $L_{t} / N_{t}$ : we do not consider possible additional "costs" or "benefits" which may result from differences in productivity $\left(Y_{t} / L_{t}\right)$ and the consumption share of GDP $\left(C_{t} / L_{t}\right)$ that may result from differences in demographic trajectory. 
Parr \& Guest: A method for socially evaluating the effects of long run demographic paths on living standards

one hour worked per week per capita in 2011(shown by the "total value" in column 4 of Table 2) and over 19 times the 2011 total consumption, which is a consumption value of $\mathrm{A} \$ 830,682$ per capita $^{36,37}$.

Table 3: Differences in components of social value and total social value in units between variant series and baseline series with extrapolated trend in labour force participation rates by age expressed on a per capita basis: Australia 2011 onwards

\begin{tabular}{|c|c|c|c|c|c|}
\hline \multirow[t]{2}{*}{ Variant Series } & \multicolumn{3}{|c|}{ Difference from Baseline Series ${ }^{a, b}$} & \multicolumn{2}{|c|}{$\begin{array}{c}\text { Modulus of Difference in } \\
\text { Total Value }{ }^{a}\end{array}$} \\
\hline & $\begin{array}{c}\text { Stable } \\
\text { Population } \\
\text { Component }\end{array}$ & $\begin{array}{c}\text { Transition Path } \\
\text { Component }\end{array}$ & $\begin{array}{c}\text { Total Social } \\
\text { Value }\end{array}$ & $\begin{array}{c}\text { As } \% \text { of } \\
\text { Social Value } \\
\text { of Baseline } \\
\text { Series }^{c}\end{array}$ & $\begin{array}{c}\text { As } \% \text { of } \\
\text { Social Value } \\
\text { in } 2011^{d}\end{array}$ \\
\hline$\overline{\mathrm{A} \text { (Constant Mortality) }}$ & 398.6 & -89.2 & 309.5 & 4.6 & 1862.4 \\
\hline $\begin{array}{l}\text { B (Net Migration }= \\
90,000)\end{array}$ & 0.0 & -23.1 & -23.1 & 0.4 & 138.9 \\
\hline $\begin{array}{c}C(\text { Net Migration }= \\
270,000)\end{array}$ & 0.0 & 14.5 & 14.5 & 0.2 & 87.1 \\
\hline $\begin{array}{l}D(\text { Net Migration }= \\
\quad 0)\end{array}$ & -67.9 & -51.6 & -119.5 & 1.8 & 719.2 \\
\hline$E(T F R=1.7)$ & 72.3 & -5.3 & 67.0 & 1.0 & 403.2 \\
\hline $\mathrm{F}(\mathrm{TFR}=2.1)$ & -45.9 & -8.1 & -53.9 & 0.8 & 324.5 \\
\hline
\end{tabular}

Notes: a. Using $g_{A}=1.5 \%$ p.a., $\rho=1.75 \%$ p.a., $\alpha=1$, and $\beta=0$.

b. Expressed as a multiple of the 2011 consumption value of one hour worked per week per capita.

c. Value of baseline series $=6476.1$ times the consumption value of one hour worked per week per capita in 2011 .

d. As multiple of consumption value of $2011 \mathrm{~L} / \mathrm{N}$ (16.6 hours worked per week per capita).

Another way of interpreting the percentage difference in value is that an immediate and sustained increase in labour force participation in all age and sex groups equivalent to $5.1 \%$ of the 2011 level would be required to offset the negative effect on social value of the forecast mortality change between 2011 and 2050. Using (10), the contributions of different time periods to this difference in values can be calculated. Only $2 \%$ of the difference in social value is realised over the period $2011-2050$ and only $9.6 \%$ by 2100 . These figures provide an indication of the limitation in truncating the projection period,

${ }^{36}$ At the initial time point of the projection (30 $0^{\text {th }}$ June 2011) one Australian dollar officially exchanged for 1.10US\$ and 0.77 Euros (Australian Taxation Office 2012).

${ }^{37}$ This figure is based on an estimated GDP for 2011 of A $\$ 1.33$ trillion and hence a value of $Y_{t} / L_{t}$ of A $\$ 3585$ per hour worked per week per person. It is based on the strong assumption that the effect of age structure on $Y_{t} / L_{t}$ is neutral. 
and that the cost of the projected mortality improvement is almost entirely the product of assumed very long-run effects.

The estimated total cost of the projected mortality improvement depends on the assumed levels of migration and fertility. Under lower (positive) levels of migration the per capita cost of the projected mortality change is higher, entirely due to a higher Transition Path Component. The greater per capita cost is the product of the concentration of the effect of projected mortality improvement in the older age groups and the generally older transition-path populations that occur under lower migration. Under lower fertility the per capita cost of the projected mortality change is greater than under higher fertility. This is largely accounted for by an increased Stable Population Component, and reflects the generally older age structures with lower fertility. Clearly from (9) the magnitude of the value of any difference in demographic trajectories will be smaller under a higher social discount rate $(\rho)$ than under a lower rate, and larger under a higher rate of productivity growth $(g)$ compared to under a lower rate.

\subsubsection{The effects of future migration on social valuations}

Since all the series with positive values of net migration approach the same terminal stable population ${ }^{21}$, the differences in social value between these series are entirely due to the differing transition paths. Table 2 shows that the magnitude of the cost of lowering migration by 90,000 is 28 times the consumption value of one hour worked per week per capita (column 4 of Table 2), which equates to $0.5 \%$ of the baseline social value (column 5), whereas the benefit from increasing migration by 90,000 is smaller at 16.5 times the consumption value of one hour worked per week per capita $(0.3 \%$ of baseline social value). The cost of lowering migration to zero is far larger $(2.6 \%$ of baseline social value) than that of lowering migration from 180,000 to 90,000 . Over half $(59.1 \%)$ of this larger cost is due to the difference in the values of the terminal stable populations of the non-zero migration and the zero migration projections. Thus whilst the cost in perpetuity of lower migration is very large in absolute terms (for example the cost of a sustained reduction in migration from 180,000 to 90,000 equates to $168.4 \%$ of 2011 national consumption (see column 6)), due to the infinitely long duration of this effect, only a very minor increase in labour force participation $(0.5 \%$ of the 2011 levels), if immediate and sustained, would be needed to counterbalance its effect on the long-run social value.

The percentages of the differences in social value with the baseline series which are realised by 2050 (21.6\% for series B (90,000 net migration per annum) and $30.1 \%$ for series C $(270,000))$ and those realised by $2100(63.3 \%$ for series B and $76.6 \%$ for series C) are considerably higher than the equivalent figures which result from the 
variations in fertility and in mortality that we consider. This reflects the transitory nature of the effects of such changes in migration levels on the age structure. As a consequence of the earlier pattern of the migration effects, the effects of variations in migration are less sensitive than the effects of variations in fertility or mortality to the assumed consumption discount rate ${ }^{38}$.

The estimated valuations of the effects of migration also depend on the fertility and mortality assumptions. With lower, sub-replacement levels of fertility the per capita benefit of higher migration and the cost of lower migration are increased, reflecting the higher proportion of the population who are surviving migrants under lower fertility scenarios. The difference in values between the positive migration projections and the zero migration projections is considerably smaller when fertility is above replacement level, because the "Stable Population Component" is zero at above replacement levels of fertility (the effect of any constant number of migrants tends to become ignorable as the population grows exponentially). Under constant as opposed to improving mortality the per capita effects of variations in net migration between different positive levels are larger.

\subsubsection{The effects of future fertility on social valuations}

Under positive net migration, projections with lower fertility have higher per capita values than those with higher fertility. The value of series $\mathrm{E}(\mathrm{TFR}=1.7)$ is higher than the baseline series by $0.8 \%$, which in turn is $0.6 \%$ higher than the value of Series $\mathrm{F}$ $(\mathrm{TFR}=2.1)$, and the fertility level which produces the highest value path is zero. For each variant the major component of the differences in social value is the "Stable Population Component" (Table 2).

The effect of any given change in the fertility level is larger under the constant mortality scenario than under the projected mortality improvement of the baseline series, reflecting the generally younger population in the absence of mortality improvement. Moreover, the effects of specified fertility changes on the valuations are smaller at lower, positive levels of migration and larger at higher levels, due entirely to changes in the "Transition Path Component". This can be explained by the relatively high concentration of the ages of newly arriving migrants in the female reproductive ages. The percentages of the differences in value with the baseline series which are realised by $2050(17.7 \%$ for series $\mathrm{E}(\mathrm{TFR}=1.7)$ and $23.9 \%$ for series $\mathrm{F}(2.1))$ and by

\footnotetext{
${ }^{38}$ The percentages of the differences in value from the baseline for series D (zero migration) are low: just $8.9 \%$ is realised by 2050 and $29.8 \%$ by 2011 .
} 
$2100(22.2 \%$ for series $\mathrm{E}$ and $34.1 \%$ for series F) are larger than those for the mortality variant series and smaller than those for the migration variant series.

The effects of changes in fertility under zero migration differ markedly from those under positive migration. Under zero migration the plot of valuations against the TFR follows an inverted U-shape, with the maximum social value corresponding to a total fertility of 2.25. This TFR is slightly lower than the TFR that maximises the value of the terminal stable population (2.35), due to the increases in the social value of the transition path as fertility reduces. With zero migration the social value of a projection with a TFR constant at 1.7 is 65.3 times the consumption value of one hour worked per week per capita less than that for a projection with a TFR of 1.9, which in turn is 145.4 times the consumption value of one hour worked per week per capita less than the social value for a TFR of 2.1. Under constant mortality at the 2011 level and zero migration the social values of constant fertility which maximise the social value of the projections are lower than those which do so under the projected improvement in mortality under the baseline scenario ${ }^{39}$.

\subsubsection{The effect of extrapolated changes in labour force participation on social valuations}

Sensitivity to age-specific labour force participation rates (LFPRs) is illustrated by an alternative scenario in which the LFPRs are extrapolated over the period between 2011 and 2021 at the linear trend rate of change from 2001 to 2011. The LFPRs remain constant from 2021 onwards. Between 2001 and 2011 LFPRs decreased for age groups below 25 years and increased for all age groups over 30 years, with the largest increases being in the pre-standard retirement age groups between ages 55 and 65 (Figure 4$)^{40}$. Thus the projected age profile for labour force participation is older than the current pattern. Increases in employment to population ratios for females are projected to be considerably greater than those for males, a pattern which was observed between 2001 and 2011. The results are reported in Table 3.

Under the extrapolated labour force participation trends the social values of all projections are greater than they are under constant patterns of participation ${ }^{41}$. The

\footnotetext{
${ }^{39}$ See Bloom et al. (2010) for explanation of the relationship between mortality and the optimal fertility for the share of population of working age in stable populations.

${ }^{40}$ Over the period 2010 to 2013 the rates of increase of labour force participation rates above age 55 were significantly slower than between 2001 and 2010 (ABS 2013b).

${ }^{41}$ For example, the value of baseline series is 6476.1 times the consumption value of one hour worked per week per capita under the extrapolated trend for labour force participation compared to 5845.5 with constant participation at the 2011 level (a 10.8\% increase).
} 
projected increase in participation produces increases in $L_{t} / N_{t}$ up to 2021 under the baseline series, more than offsetting the effects of projected demographic change. A comparison of the results of Table 3 with Table 2 shows that the effects of the projected mortality improvement on the social valuation is smaller under the projected changes to workforce participation than they are under continuation of the current patterns of participation. This is largely the product of the larger projected mortality improvements being on the older age groups and the effect of this change on $L_{t} / N_{t}$ being reduced by the larger projected increases in the participation rates in the older ages. The effects of changes to migration are also decreased slightly by the projected changes in participation. In contrast, the effects of fertility change on the social valuation are larger under the extrapolated trend for labour force participation rates than under constant participation rates. The increased effect of fertility reflects the growing difference between participation in the under- 20 age range and the older age groups, and the greater effects of fertility on proportions of population in the younger ages than on those in the older ages (Bloom et al. 2010).

Figure 4: Employment to population ratios by age and sex: Australia 2001 and 2011

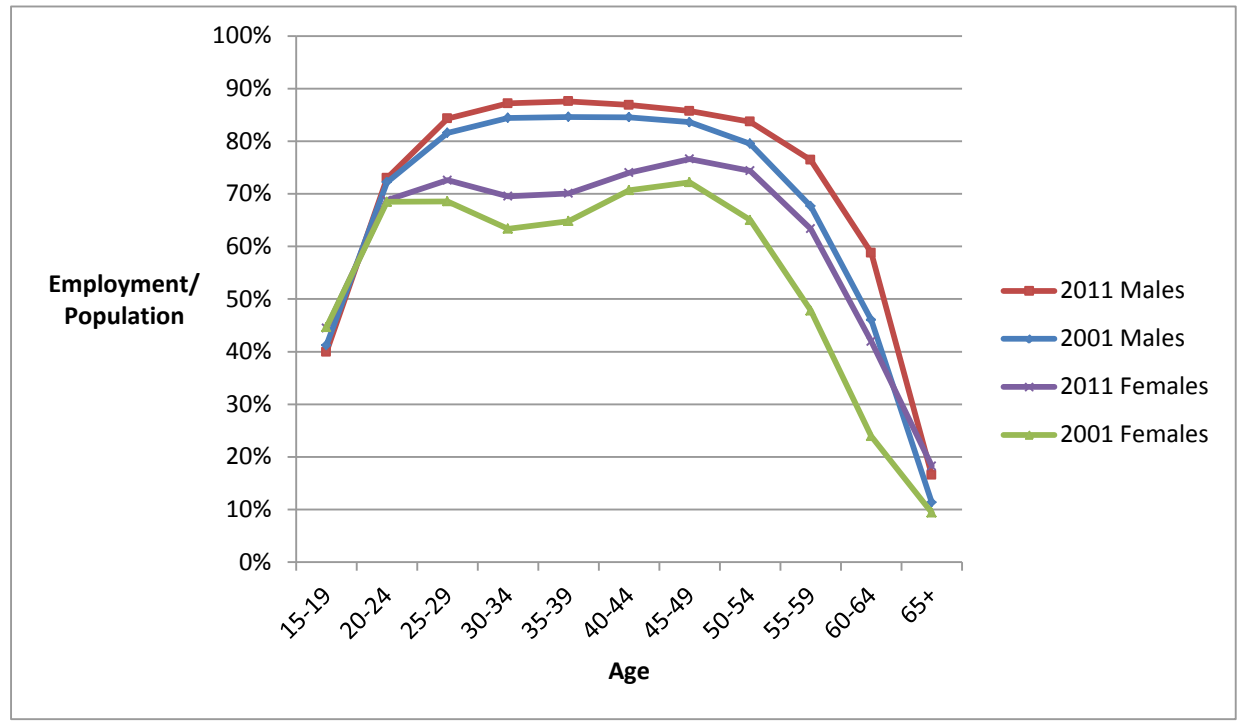




\subsubsection{The effect of weighting for consumption needs}

Weighting for consumption needs using the weights of Cutler et al. (1990) magnifies the effects on the social valuation of changes in proportion of the population aged over 65 years and shrinks the effects of changes in the proportion aged under 20 years. A comparison of Table 4 with Table 2 shows that the effect of the projected mortality improvement is considerably greater on the consumption-weighted valuations than on the unweighted valuation, reflecting the disproportionate effect of the projected mortality change on the older age groups. The effects of changes to net migration are also greater on the valuation relative to the consumption-needs weighted populations than the valuation relative to the unweighted population. The results for the two methods of consumption weighting we consider are similar.

The major difference between the valuations' relative consumption need-weighted populations and the unweighted populations is in the change of the signs for the effects of fertility. Figure 5 shows that crossovers in the value of hours worked to the (Cutler et al. 1990) consumption-weighted population occur roughly 50 years after the start of the projection $^{42,43}$. Table 4 shows that under the Cutler et al. consumption-needs weighting the social value of the baseline series (TFR $=1.9)$ is very slightly greater than that for the low fertility projection $(\mathrm{TFR}=1.7)$, and less than that for the higher fertility projection (TFR $=2.1$ ). Both the signs and the magnitudes of these differences in social value by fertility depend on the assumed trends for mortality and labour force participation $^{44}$, and on the consumption-needs weights used and the consumption discount rate. Further investigation finds a global maximum for the social values of the projections series with the baseline mortality and migration corresponding to a TFR of $3.07^{45,46}$. Under the weighting of Guest and McDonald (2001), both the low fertility series $(\mathrm{TFR}=1.7)$ and the high fertility series $(\mathrm{TFR}=2.1)$ have a slightly higher value than the baseline.

\footnotetext{
${ }^{42}$ The social value for TFR $=1.7$ first falls below the baseline $($ TFR $=1.9)$ in 2058 , which in turn first falls below that for TFR $=2.1$ in 2061 .

${ }^{43}$ The contributions of differences in particular years to the difference in social value reflect the effects of consumption discounting as well as the differences in $L_{t} / N_{t}$. Thus the magnitude of the contributions of future years reduces.

${ }^{44}$ Under the increasing labour force participation projection the value of the TFR $=1.7$ variant is higher than that of the baseline series (TFR $=1.9$ ).

${ }^{45}$ The global maximum for the value of the terminal stable population occurs when the TFR $=3.25$.

${ }^{46}$ Under the extrapolated trend for labour force participation the TFR which produces the maximum value is reduced to 2.79
} 
Table 4: Differences in components of social value and total social value in units between variant series and baseline series with constant labour force participation rates expressed on consumption needs-weighted basis: Australia 2011 onwards

\begin{tabular}{|c|c|c|c|c|c|}
\hline \multirow[t]{2}{*}{ Variant Series } & \multicolumn{3}{|c|}{ Difference from Baseline Series $^{\text {a,b }}$} & \multicolumn{2}{|c|}{$\begin{array}{c}\text { Modulus of Difference in } \\
\text { Total Value }\end{array}$} \\
\hline & $\begin{array}{c}\text { Stable } \\
\text { Population } \\
\text { Component }\end{array}$ & $\begin{array}{c}\text { Transition } \\
\text { Path } \\
\text { Component }\end{array}$ & $\begin{array}{l}\text { Total Social } \\
\text { Value }\end{array}$ & $\begin{array}{c}\text { As } \% \text { of } \\
\text { Value of } \\
\text { Baseline } \\
\text { Series }^{c}\end{array}$ & $\begin{array}{c}\text { As } \% \text { of } \\
\text { Social Value } \\
\text { in } 2011^{d}\end{array}$ \\
\hline \multicolumn{6}{|l|}{ Cutler et al. 1990} \\
\hline A (Constant Mortality) & 542.0 & -117.5 & 424.5 & 6.8 & 2468.1 \\
\hline $\begin{array}{l}B(\text { Net Migration }= \\
90,000)\end{array}$ & 0.0 & -40.8 & -40.8 & 0.7 & 237.0 \\
\hline $\begin{array}{c}C(\text { Net Migration }= \\
270,000)\end{array}$ & 0.0 & 24.7 & 24.7 & 0.4 & 134.2 \\
\hline $\mathrm{D}($ Net Migration $=0)$ & -105.4 & -106.5 & -211.9 & 3.7 & 1232.2 \\
\hline$E(T F R=1.7)$ & 11.9 & -15.3 & -3.4 & 0.1 & 19.6 \\
\hline $\mathrm{F}(\mathrm{TFR}=2.1)$ & 25.4 & -5.1 & 20.3 & 0.4 & 117.8 \\
\hline \multicolumn{6}{|l|}{$\begin{array}{l}\text { Guest and McDonald } \\
2001\end{array}$} \\
\hline A (Constant Mortality) & 545.4 & -199.8 & 425.5 & 6.5 & 2473.6 \\
\hline $\begin{array}{l}B(\text { Net Migration }= \\
90,000)\end{array}$ & 0.0 & -38.1 & -38.1 & 0.6 & -221.4 \\
\hline $\begin{array}{c}C(\text { Net Migration }= \\
270,000)\end{array}$ & 0.0 & 24.8 & 24.8 & 0.4 & 144.5 \\
\hline $\mathrm{D}($ Net Migration $=0)$ & -101.7 & -103.3 & -205.0 & 3.4 & -1192.9 \\
\hline$E(T F R=1.7)$ & 20.3 & -14.4 & 6.0 & 0.1 & 35.1 \\
\hline $\mathrm{F}(\mathrm{TFR}=2.1)$ & 16.4 & -5.8 & 10.6 & 0.2 & 65.4 \\
\hline
\end{tabular}

Notes: a. Using $g_{A}=1.5 \%$ p.a., $\rho=1.75 \%$ p.a., $\alpha=1$, and $\beta=0$.

b. Expressed as a multiple of the 2011 the consumption value of one hour worked per week per equivalent consumer.

\subsubsection{The effect of diminishing returns to scale on the valuations}

Under diminishing returns to scale ( $\alpha$ less than one) or increasing returns to scale ( $\alpha$ greater than one) the value of each element of each series is affected by the absolute size of the labour force at that time. Diminishing returns to scale lower the value of larger populations relative to smaller populations. Table 5 shows the valuations for 
alpha equal to $0.95^{47}$. Since under all the projections for Australia that we consider (except series D which has zero migration) the labour force size increases continuously over time, the influence on the difference in total value of age structure differences in the more distant future relative to those in the more immediate future is reduced under such diminishing returns to scale.

Figure 5: Effects of varying fertility on support ratio relative to consumptionsneed-adjusted population: Baseline $(T F R=1.9)$ vs $T F R=1.7$ and TFR $=2.1$

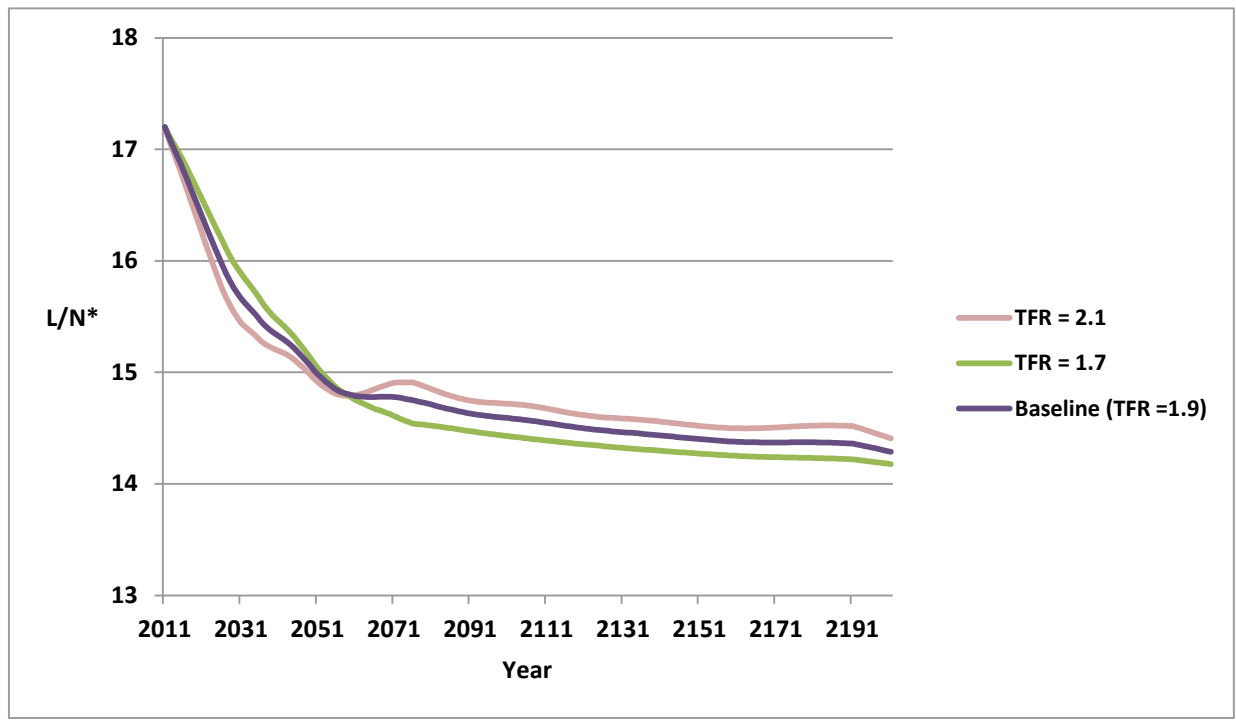

Note: $\mathrm{L} / \mathrm{N}^{*}$ weights the number aged $0-19$ years by 0.72 and the number aged 65 and above years by 1.27 .

In contrast to the pattern of projections with higher migration having higher value under constant returns (Table 2), under diminishing returns to scale at the level we have used, projections with lower migration have higher total values than those with higher migration. This occurs because the small age-structure-related benefits of higher migration are more than offset by the implied costs of a larger population size. Of note is that, whereas with constant returns to scale the stable population components of the

${ }^{47}$ For the purposes of comparison between Table 5 and the basic constant returns simulation in Table 2 the value of $A_{t}$ in equation (3) has been chosen to equate the value of $Y / N$ in table 5 with the value of $Y / N=L / N$ $=16.6$ in Table 2 . 
differences in value are zero, under diminishing returns the larger terminal stable populations which result from higher migration have lower levels of output per capita than those for lower migration projections.

Under diminishing returns to scale the benefit of a lower fertility relative to higher fertility is increased by the smaller labour force sizes from fifteen years and more after the start of the projection that result under lower fertility. The larger difference in value between Series E $($ TFR $=1.7)$ and the baseline $($ TFR $=1.9)$ under the diminishing returns scenario illustrates this (compare column 4 of Table 5 to column 4 of Table 2). Under above replacement fertility levels the value of $L^{\alpha} / \mathrm{N}$ asymptotically approaches zero. The much larger cost expressed as a percentage of the value of the baseline for the contrast between series F $(\mathrm{TFR}=2.1)$ and the baseline $(\mathrm{TFR}=1.9)$ (compare column 4 of Table 5 to column 4 of Table 2) reflects this implication of exponential growth.

Table 5: Differences in components of social value and total social value in units between variant series and baseline series with diminishing returns to scale expressed on a per capita basis: Australia 2011 onwards

\begin{tabular}{|c|c|c|c|c|c|}
\hline \multirow[t]{2}{*}{ Variant Series } & \multicolumn{3}{|c|}{ Difference from Baseline Series ${ }^{a, b}$} & \multicolumn{2}{|c|}{$\begin{array}{c}\text { Modulus of Difference in } \\
\text { Total Value }\end{array}$} \\
\hline & $\begin{array}{c}\text { Stable } \\
\text { Population } \\
\text { Component }^{c}\end{array}$ & $\begin{array}{c}\text { Transition } \\
\text { Path } \\
\text { Component }^{\mathrm{c}}\end{array}$ & $\begin{array}{l}\text { Total } \\
\text { Social } \\
\text { Value }\end{array}$ & $\begin{array}{c}\text { As } \% \text { of } \\
\text { Social Value } \\
\text { of Baseline } \\
\text { Series }^{d}\end{array}$ & $\begin{array}{c}\text { As } \% \text { of } \\
\text { Social } \\
\text { Value in } \\
2011^{\mathrm{e}}\end{array}$ \\
\hline$\overline{\mathrm{A} \text { (Constant Mortality) }}$ & 158.2 & -42.1 & 116.1 & 5.6 & 1873.6 \\
\hline $\begin{array}{l}\mathrm{B}(\text { Net Migration }= \\
90,000)\end{array}$ & 183.9 & -69.9 & 114.0 & 2.1 & 685.8 \\
\hline $\begin{array}{c}C(\text { Net Migration }= \\
270,000)\end{array}$ & -104.6 & 31.5 & -73.1 & 1.3 & 440.0 \\
\hline$E(T F R=1.7)$ & 257.4 & -92.3 & 165.1 & 3.0 & 993.7 \\
\hline $\mathrm{F}(\mathrm{TFR}=2.1)$ & -5213.1 & 4299.9 & -913.3 & 16.6 & 5495.9 \\
\hline
\end{tabular}

Notes: a. Using $g_{A}=1.5 \%$ p.a., $\rho=1.75 \%$ p.a., $\alpha=0.95$, and $\beta=0$.

b. Expressed as a multiple of the 2011 the consumption value of one hour worked per week per capita.

c. To facilitate comparison with Table $2 \mathrm{~A}_{0}$ has been scaled to equate $\mathrm{Y} / \mathrm{N}=16.6$.

d. Value of baseline series $=5,511.0$ times the consumption value of one hour worked per week per capita in 2011 .

e. As multiple of consumption value of 2011 Y/N (16.6).

The social cost of the projected mortality improvement expressed as a percentage of the value of the baseline series, shown in column 4 in Table 5, is larger under diminishing returns to scale than under constant returns to scale (Table 2), because, in addition to its detrimental effects on age structure, mortality improvement increases the 
size of the labour force to the further detriment of output per capita. However, when measured as a percentage of the value of 2011 output, the cost of projected mortality improvement is smaller under the diminishing returns to scale scenario than under constant returns (columns 5 in Tables 5 and 2), because under diminishing returns the influence of the more distant future, when the projected labour force size is larger, is reduced.

\subsubsection{The effect of aversion to intergenerational inequality on social valuations}

With a positive value for the parameter for aversion to intergenerational inequality $(\beta)$ (Appendix A) the proportionate influence on the social valuation of projected values for time points in the more distant future is reduced ${ }^{48,}{ }^{49}$. Table 6 shows that, with the higher discount rate resulting from the positive value of $\beta$, the direction of the effect of fertility on the consumption needs-weighted valuation is changed: the series TFR $=1.7$ has a higher social value than the baseline series which, in turn, has a higher social value than that of the high fertility series $(\mathrm{TFR}=2.1)^{50}$. This reflects the reduced proportionate influence on the valuations of the 'post-crossover' pattern of higher values of $L_{t} / N_{t}$ with higher fertility 47-51 years after the start of the projection, shown by Figure 5 . The sign of the effect of lower, as opposed to higher, fertility on the valuation depends on the estimated size of the parameter measuring aversion to intergenerational inequality $(\beta)$, the consumption weights, the assumed trajectory for labour force participation rates, and also on the choice of social discount rate $(\rho)^{51}$. It also depends on the specified assumptions for migration and mortality. For example, if a constant net migration of less than 92,000 per annum is assumed, as opposed to the baseline level of 180,000 per annum, a projection with total fertility of 1.7 will have a

\footnotetext{
${ }^{48}$ This assumes the assumed rate of productivity growth, $g_{A}$, is positive.

${ }^{49}$ Note the units of measurement for the components of the valuations in Table 5 are not comparable to those for Tables 2 to 4 .

${ }^{50}$ The signs of the effects of these differences in fertility depend on the assumed trend for labour force participation. Under the extrapolated trend for labour force participation the social value of the TFR $=1.7$ series relative to the consumption needs-weighted population still exceeds that of the baseline (TFR=1.9) which, in turn, exceeds that for TFR $=2.1$. This reflects the higher rate of discount of the effects of future increases to labour force participation.

${ }^{51}$ For example, if the social discount rate $(\rho)$ is less than $1.1 \%$, the value of the TFR $=1.7$ series is less than that of the baseline, and if it is less than $0.8 \%$ the value of the TFR $=2.1$ series is greater than that of the baseline series, when the Cutler et al (1990) consumption needs weights, the 2011 labour force participation rates, and an aversion to intergenerational inequality parameter $(\beta)$ of 1.4 are applied.
} 
Parr \& Guest: A method for socially evaluating the effects of long run demographic paths on living standards

lower (Cutler et al. 1990) consumption needs-weighted value than a series with the baseline level of total fertility $(1.9)^{52}$.

Table 6: Differences in components of social value and total social value in units between variant series and baseline series for unweighted and consumption needs-weighted populations with incorporation of aversion to intergenerational inequality: Australia 2011 onwards

\begin{tabular}{|c|c|c|c|c|c|}
\hline \multirow[t]{2}{*}{ Variant Series } & \multicolumn{3}{|c|}{ Difference from Baseline Series $^{a, b}$} & \multicolumn{2}{|c|}{$\begin{array}{c}\text { Modulus of Difference in } \\
\text { Total Value }{ }^{\mathrm{a}}\end{array}$} \\
\hline & $\begin{array}{c}\text { Stable } \\
\text { Population } \\
\text { Component }\end{array}$ & $\begin{array}{c}\text { Transition } \\
\text { Path } \\
\text { Component }\end{array}$ & $\begin{array}{c}\text { Total Social } \\
\text { Value }\end{array}$ & $\begin{array}{c}\text { As } \% \text { of } \\
\text { Value of } \\
\text { Baseline } \\
\text { Series }\end{array}$ & $\begin{array}{c}\text { As } \% \text { of } \\
\text { Social Value } \\
\text { in } 2011^{c}\end{array}$ \\
\hline \multicolumn{6}{|c|}{ With $\mathrm{N}$ as (unweighted) Total Population } \\
\hline$\overline{\mathrm{A} \text { (Constant Mortality) }}$ & & -0.73 & 0.31 & 0.83 & 37.04 \\
\hline $\begin{array}{l}\text { B (Net Migration }= \\
90,000)\end{array}$ & 0.00 & -0.17 & -0.17 & 0.48 & 21.53 \\
\hline $\begin{array}{l}C(\text { Net Migration }= \\
270,000)\end{array}$ & 0.00 & 0.12 & 0.12 & 0.34 & 15.30 \\
\hline $\mathrm{D}($ Net Migration $=0)$ & -0.20 & -0.28 & -0.48 & 1.30 & 58.48 \\
\hline$E(T F R=1.7)$ & 0.14 & -0.01 & 0.14 & 0.37 & 16.75 \\
\hline $\mathrm{F}(\mathrm{TFR}=2.1)$ & -0.07 & -0.07 & -0.14 & 0.40 & 17.83 \\
\hline \multicolumn{6}{|c|}{ With N Weighted for Relative Consumption Needs ${ }^{d}$} \\
\hline A (Constant Mortality) & 1.38 & -0.97 & 0.41 & 1.15 & 51.68 \\
\hline $\begin{array}{l}\mathrm{B}(\text { Net Migration }= \\
90,000)\end{array}$ & 0.00 & -0.26 & -0.26 & 0.71 & 32.19 \\
\hline $\begin{array}{c}C(\text { Net Migration }= \\
270,000)\end{array}$ & 0.00 & 0.19 & 0.19 & 0.51 & 23.10 \\
\hline D $($ Net Migration $=0)$ & -0.29 & -0.41 & -0.70 & 1.93 & 87.19 \\
\hline$E(T F R=1.7)$ & 0.03 & 0.00 & 0.13 & 0.08 & 3.79 \\
\hline $\mathrm{F}(\mathrm{TFR}=2.1)$ & -0.07 & -0.11 & -0.04 & 0.12 & 5.26 \\
\hline
\end{tabular}

Notes: a. Using $g_{A}=1.5 \%$ p.a., $\rho=1.75 \%$ p.a., and $\beta=1.4$.

b. Units of social utility per (unweighted or weighted) person.

c. $2011 \mathrm{~L} / \mathrm{N}=16.6$ hours worked per week per unweighted person and 17.2 hours worked per week per consumption needweighted person.

d. Using the weights of Cutler et al. (1990).

\footnotetext{
${ }^{52}$ This also assumes mortality follows the baseline series projected improvement, constant labour force participation, $g_{A}=1.5 \%, \rho=1.75 \%$, and $\beta=1.4$.
} 
Table 6 also shows that the percentages of the differences in social value which are due to the differences in the Stable Population Components are far smaller than those which are estimated with lower discount rates. The social value of the difference between Series A (constant mortality) and the baseline series, expressed as a percentage of the social value of the baseline series and as a percentage of 2011, is particularly heavily affected.

\section{Discussion and conclusion}

This paper proposes a simple and transparent method for socially evaluating the effects of certain infinitely long demographic paths on employment-to-population/consumer ratios, and hence material living standards. The method unifies the valuation of stable populations with the valuation of transition paths towards these stable populations to produce a single measure of social value and, hence, a clear criterion for preference between long-term demographic paths and measurement of the magnitudes of the values of such differences (Striessnig and Lutz 2012, 2014; Sánchez-Romero 2013; Lau 2014). In doing so the analysis demonstrates both the limitations of comparing demographic paths using a finite projection window and the limitations of considering stable populations alone. The method incorporates judgements of a 'social planner' as well as assumptions on the paths of mortality, migration, fertility, labour force participation, productivity growth, and relative consumption needs.

For simplicity of illustration of the framework proposed, our model assumes the only productive factor is raw labour. The baseline valuations assume neutrality of the effects of population age structure, fertility, mortality, and migration on average labour productivity and the consumption share of GDP ${ }^{53}$. These are strong assumptions (Jones 2002; Day and Dowrick 2004; Kelley and Schmidt 2005; Guest 2007; Skirbekk 2008; Lee and Mason, 2010; Williamson 2013). The age structure of the population can affect the national savings rate (Auerbach and Kotlikoff 1987; 1992; Lee et al. 2000, 2001; Williamson 2013). Fertility and mortality levels could also affect savings and may in turn be affected by living standards (Preston 1975; Lee et al. 2000; 2001; Sobotka et al. 2011). According to Auerbach and Kotlikoff (1992), the projected decrease in the rate of increase in savings in the United States will be less than the projected decrease in the rate of labour supply, implying an increase in the capital-to-labour ratio to the benefit of labour productivity and wages, and the lowering of interest rates. The effect of population ageing, and of fertility, mortality, and migration patterns which are

\footnotetext{
${ }^{53}$ The diminishing returns to scale scenario, however, does allow the variables which affect population, and
} hence labour force size, fertility, mortality, and migration, to affect output per worker. 
associated with increased ageing, thus could be less unfavourable than is shown by our model. Taxation revenues and government expenditures will also be affected by population age change (Auerbach and Kotlikoff 1987, 1992; Australian Treasury 2010). Moreover, fertility levels may be related to "child quality" and hence the productivity of cohorts after they have entered the labour force (Becker 1981; Parr 2006; Lattimore and Pobke 2008; Williamson 2013). If so, then the value of low fertility in our examples may be understated in our basic model ${ }^{54}$. The selectivity of in- and out- international migration and urban-rural internal migration may also affect average labour productivity (Williamson 2013).

Whilst for simplicity the illustrative examples in this paper omit to do so, the framework proposed could be extended straightforwardly to incorporate differential effects of age groups on labour productivity (Appendix B). It can also be modified to incorporate effects of other aspects of the demographic composition of populations, such as educational attainment, on labour force participation, productivity, and consumption (Kelley and Schmidt 2005; Striessnig and Lutz 2012, 2014) ${ }^{55}$. Further work is needed to estimate the sensitivity of outcomes to assumed non-neutral effects of population age structure, fertility, mortality, and migration on other potentially significant determinants of living standards, such as saving, labour productivity, health, and educational attainment.

Our method assesses social value based on projected paths of average living standards only. Modification of the valuation process to consider the difference between average living standards and a subjectively chosen critical level for living standards is straightforward. Moreover, Appendix A shows how social aversion to inequality in intertemporal living standards can be incorporated within our framework.

Our social valuation framework considers an infinite time horizon. An alternative approach to social valuation which has been considered in the literature involves assessing the lifetime utility of the current population (or the social planner) by summing values across total future expected person years lived or a socially discounted variant (Blackorby and Donaldson 1984; Duclos and Housseini 2013). Under this egocentric alternative approach, improvements in mortality are allowed to add to utility through increasing the numbers of years over which the utility of living standards (or living standards above a critical level) of the population (or social planner) accrues. However, the longer-term prospects affecting future additions (births plus migrants), including future births that are a legacy of the mortality change, are ignored. Moreover,

\footnotetext{
${ }^{54}$ The diminishing returns scenario illustrates this.

${ }^{55}$ The simulations in this paper are for independently determined values of data inputs: the extension to social valuations of interdependent assumptions (for example, effects of fertility or migration on rates of labour force participation) also is feasible.
} 
the very low cumulative shares of the "mortality effect" (and the only modest shares of "fertility effects" and "migration effects") which are realised by 2050 and 2100 show truncation of the period of assessment would lead to serious underestimation of the significance of these effects on future dependency and output. Assessments of changes in demographic parameters under a lifetime utility approach are therefore myopic and incomplete.

Our framework is based on consideration of average living standards and utility over time. Another alternative is the "total utility" approach, which aggregates utility according to population size and age distribution. However, such total utility approaches tend to support the maximisation of population size irrespective of living standards (Ng 1986; Duclos and Housseini 2013).

The social valuation method is applied to long-term demographic paths for Australia. An important underlying assumption is that net immigration, predominantly concentrated in the younger working ages, will continue over the long run. This is an appropriate assumption for such a country with a long history of immigration. For below-replacement long-term fertility levels the age structures of the stable (and stationary) populations to which the projections converge are quite different from the stable populations which result from under-zero migration (Pollard 1973; Espenshade et al. 1982; Cerone 1987; Schmertmann 1992). Our consideration of examples with very long-run net immigration represents a further point of difference from the approaches of Weil (1999) and Bloom et al. (2010). The results show the cost of prospective mortality improvement to 2050 implied in the baseline. The cost depends on the needs of the older age groups relative to those of the younger age groups, especially their health needs, and as such depends on health policy intervention (Rice and Feldman 1983; Rice and Fineman 2004, Prskawetz and Sambt 2014) ${ }^{56}$. The simulations illustrate how the potential cost of increased longevity may be offset by increases in labour force participation of older workers, with implications for policies encouraging older workers to remain in the workforce. Similarly, higher fertility levels and higher migration levels would also somewhat reduce the costs of increased longevity.

The valuations in this paper provide measurements of the economic value of the generally young age structure of net immigration to Australia. Whilst higher as opposed to lower immigration has no effect on the age structure of the terminal stable populations in our simulations ${ }^{21}$, the long-run value of a higher level of immigration can nonetheless be substantial: for example, under our model the benefit of net migration of

\footnotetext{
${ }^{56}$ Not shown in our valuations is the distribution of the population within the broad age groups $(0-19,20-64$, and 65 and over) to which we apply consumption needs weights, which will also affect the valuations if the underlying needs vary within these age groups. For example, greater health-related needs of the oldest-old will affect the need of the over- 65 age group, as the proportionate share in the oldest-old age range changes.
} 
Parr \& Guest: A method for socially evaluating the effects of long run demographic paths on living standards

180,000 per annum compared to 90,000 per annum equates to $\mathrm{A} \$ 100,311$ per capita (US\$ 91,192 per capita) ${ }^{57}$. Such substantial amounts are the product of the persistence of age structure differences over a very long duration of the transition to the stationary population. The benefit of the age structure effects of higher migration would be smaller if fertility levels fell or if future mortality improvement were below our assumed level.

Over the period between 2001 and 2008 Australia's total fertility rate increased from 1.73 to 2.02, before falling back to 1.93 in 2012 (ABS 2013a; Parr and Guest 2011). Completed fertility to age 50 has fallen gradually to 2.08 births per woman. Under Australia's former Howard-led government (1996-2007), a pronatalist policy intent was apparent (Heard 2006; UNPD 2008; Parr and Guest 2011). Both reviews of the international literature and empirical evaluations for Australia suggest the effects on fertility of pronatalist policies have generally been slight (McDonald 2006; Gauthier 2007; Parr and Guest 2011). The simulations here show that, within the narrow range of Australia's recent fertility experience, whether higher fertility is more valuable or less valuable than lower fertility depends on the consumption needs of the older age groups relative to those of the younger age groups: in the case of equal consumption needs lower fertility is unequivocally preferable to higher fertility, but the opposite is the case with age-specific consumption needs using the weightings in Cutler et al. (1990). The long-run social value of an increased fertility rate also depends on whether labour force participation at older ages continues to increase (a pattern which has been evident in recent years). Under extrapolation of the recent trends in participation the value of higher fertility is reduced ${ }^{32}$ : for example, with an extrapolation of recent participation trends to 2021, a TFR of 1.7 becomes more socially valuable than a rate of 1.9 , even with consumption weighting for the greater needs of the aged ${ }^{58}$. The paper also illustrates how the value of higher as opposed to lower fertility will also depend on whether diminishing, constant, or increasing returns to scale, specifically to the total labour force size, apply in the future.

The simulations also illustrate how the social value of fertility rates depends on value judgements about intergenerational equity, a matter of philosophical debate in the literature (Ramsey 1928; Pigou 1932; Chichilnisky 1997; Stern 2007; Weitzman 2007). Defining optimum fertility as the long-run value of the TFR that maximises social value, simulations show the optimum fertility varies widely between different assumptions for relative consumption needs: for example, under our simplest form of

\footnotetext{
${ }^{57}$ The conversion from the discounted hours per week per capita to dollar amounts used the 2011 ratio of GDP to total hours worked and the exchange rate at 30/6/2011.

${ }^{58}$ The change in the sign resulting from a change in fertility between these values is also dependent on the values of other data inputs to the model, including the social discount rate.
} 
the model (which in effect applies the same weight to all age groups) the optimum fertility is zero, whereas under the consumption weights used in Cutler et al. (1990) it increases to 3.07. Higher levels of mortality, lower net migration, increases in labour force participation rates in the older ages, and higher rates of consumption discounting all reduce the optimum fertility level. As such, 'optimal fertility' is a subjectively based, often unattainable, and invariably moving target.

\section{Acknowledgements}

This research was supported by an Australian Research Council (ARC) Discovery Grant funding scheme (project number DP0984378). We are grateful to Amy Lo for research assistance, to Dr. Jackie Li of Nanyang Technological University, Singapore for supplying the mortality projections, and to two anonymous reviewers for their suggestions. 


\section{References}

Arthur, W.B. and McNicoll, G. (1978) Samuelson, population and intergenerational transfers. International Economic Review 19(1): 241-246.

Auerbach, A.J. and Kotlikoff, L.J. (1987). Dynamic Fiscal Policy. Cambridge: Cambridge University Press.

Auerbach, A.J. and Kotlikoff, L.J. (1992) The impact of the demographic transition on capital formation. The Scandinavian Journal of Economics 94(2): 281-295. doi: $10.2307 / 3440453$.

Australian Bureau of Statistics, (ABS) (2012a). Australian Demographic Statistics. Canberra: Commonwealth of Australia.

Australian Bureau of Statistics, (ABS) (2012b). The Labour Force: Time Series Spreadsheets. Canberra: Commonwealth of Australia.

Australian Bureau of Statistics, (ABS) (2012c). Migration Australia 2011-12. Canberra: Commonwealth of Australia.

Australian Bureau of Statistics, (ABS) (2013a). Births. Canberra: Commonwealth of Australia.

Australian Bureau of Statistics, (ABS) (2013b). The Labour Force, Australia Detailed-Electronic Delivery. Canberra: Commonwealth of Australia.

Australian Taxation Office, (ATO) (2012). Foreign exchange rates: Translation (conversion) to Australian dollars - foreign currency exchange rates to use: 2010-11 Income Year [electronic resource]. https://www.ato.gov.au/Rates/ Foreign-exchange-rates/?page=4\#End_of_financial_year_rates.

Australian, Treasury (2010). Australia to 2050: Future challenges. The 2010 intergenerational report overview [electronic resource]. http://archive.treasury. gov.au/igr/igr2010/Overview/pdf/IGR_2010_Overview.pdf.

Becker, G. (1981). A Treatise on the Family. Cambridge, Massachusetts: Harvard University Press.

Blackorby, C. and Donaldson, D. (1984) Social criteria for evaluating population change. Journal of Public Economics 25(1-2): 13-33. doi:10.1016/00472727(84)90042-2. 
Bloom, D.E., Canning, D., Fink, G., and Finlay, J.E. (2010). The cost of low fertility in Europe. European Journal of Population 26(2): 141-158. doi:10.1007/s10680009-9182-1.

Commonwealth, of Australia (2011). Sustainable Australia - Sustainable Communities. Canberra: Commonwealth of Australia [electronic resource]. http://www. environment.gov.au/resource/sustainable-australia-sustainable-communitiessustainable-population-strategy-australia.

Carnes, B.A., Olshansky, S.J., and Grahn, D. (2003). Biological evidence for limits to the duration of life. Biogerontology 4(1): 31-45. doi:10.1023/A:1022425317536.

Cerone, P. (1987). On stable population theory with immigration. Demography 24(3): 431-438. doi:10.2307/2061308.

Chichilnisky, G. (1997). What is sustainable development? Land Economics 73(4): 467-491. doi:10.2307/3147240.

Cutler, D., Poterba, J., Sheiner, L., and Summers, L. (1990). An aging society: opportunity or challenge? Brookings Papers on Economic Activity 1990(1): 1-73. doi:10.2307/2534525.

Day, C. and Dowrick, S. (2004). Ageing Economics: Human Capital, Productivity and Fertility. Agenda 11(1): 3-20.

Department of Immigration and Citizenship, (DIAC) (2013) Australia's Migration Trends 2011-12. Canberra: Commonwealth of Australia.

Duclos, J.-Y. and Housseini, B. (2013) Life quantity, life quality and longevity: an intertemporal social evaluation framework. Clermont-Ferrand: FERDI, FERDI Development Policies Working Paper Series No. 79.

Espenshade, T.J., Bouvier, L.F., and Arthur, W.B. (1982). Immigration and the Stable Population Model. Demography 19(1): 125-133. doi:10.2307/2061132.

Gauthier, A.H. (2007). The impact of family policies on fertility in industrialized countries: a review of the literature. Population Research and Policy Review 26(3): 323-346. doi:10.1007/s11113-007-9033-x.

Guest, R. (2007). Can OECD countries afford demographic change? Australian Economic Review 40(2): 149-164. doi:10.1111/j.1467-8462.2007.00456.x.

Guest, R. and McDonald, I.M. (2001) Ageing, Immigration and Optimal National Saving in Australia. Economic Record 77(237): 117-134. doi:10.1111/14754932.00008. 
Guest, R. and Parr, N. (2010) The effects of family benefits on childbearing decisions: a household optimising approach applied to Australia. Economic Record 86(275): 609-619. doi:10.1111/j.1475-4932.2010.00663.x.

Guest, R. and Parr, N. (2013). Family policy and couple's labour supply: an empirical assessment. Journal of Population Economics 26(4): 1631-1660. doi:10.1007/ s00148-012-0421-0.

Heard, G. (2006). Pronatalism under Howard. People and Place 14(3): 12-25.

Jones, C. (2002). Sources of U.S. economic growth in a world of ideas. American Economic Review 92(1): 220-239. doi:10.1257/000282802760015685.

Kelley, A.C. and Schmidt, R.M. (2005) Evolution of recent economic - demographic modeling: a synthesis. Journal of Population Economics 18(2): 275-300. doi:10.1007/s00148-005-0222-9.

Kerr, S.P. and Kerr, W.R. (2011). The economic effects of immigration: a survey. Cambridge, Massachusetts: National Bureau of Economic Research, NBER Working Paper Series 16736.

Kirman, A. (1992). Whom or what does the representative individual represent? Journal of Economic Perspectives 6(2): 117-136.

Lattimore, R. and Pobke, C. (2008). Recent trends in Australian fertility. Canberra: Australian Government, Australian Government Productivity Commission staff working paper.

Lau, S. (2014). Fertility and mortality changes in an overlapping generations model with realistic demography. Economic Modelling 38: 512-521. doi:10.1016/ j.econmod.2014.01.028.

Lee, R.D. (1980) Age structure intergenerational transfers and economic growth: an overview. Revue économique 31(6): 1129-1156.

Lee, R. and Mason, A. (2010). Fertility, human capital, and economic growth over the demographic transition. European Journal of Population/Revue européenne de Démographie 26(2): 159-182.

Lee, R., Mason, A., and Miller, T. (2000) Life-cycle saving and the demographic transition in Eastern and Southeastern Asia. Population and Development Review 26(Supp.): 194-219. 
Lee, R., Mason, A., and Miller, T. (2001) Saving, wealth, and the demographic transition in East Asia. In: Mason, Andrew (ed.). Population change and economic development in East Asia: challenges met, opportunities seized. Stanford: Stanford University Press.

Li, J. (2013). A Poisson common factor model for projecting mortality and life expectancy jointly for females and males. Population Studies 67(1): 111-126. doi:10.1080/00324728.2012.689316.

Malmberg, B. (2006). Global population ageing, migration and european external policies. Final report. Stockholm: Institute for Future Studies.

Massey, S.J.L. and Parr, N. (2012). The socioeconomic status of migrant populations in regional and rural Australia and its implications for future population policy. Journal of Population Research 29(1): 1-21. doi:10.1007/s12546-011-9079-9.

McDonald, P. (2006). Low fertility and the state: the efficacy of policy. Population and Development Review 32(3): 485-510. doi:10.1016/j.fertnstert.2006.07.1078.

McDonald, P. and Temple, J. (2010). Immigration, labour supply and per capita gross domestic product: Australia 2010-2050 [electronic resource]. http://www.immi.gov.au/media/publications/research/_pdf/labour-supply-gdp2010-2050.pdf.

Ng, Y.-K. (1986) Social criteria for evaluating population change: an alternative to the Blackorby-Donaldson criterion. Journal of Public Economics 29(3): 375-381. doi:10.1016/0047-2727(86)90036-8.

Nordhaus, W.D. (2007). A review of the Stern review on the economics of climate change. Journal of Economic Literature XLV(Sept.): 686-702. doi:10.1257/ jel.45.3.686.

OECD (2006). Live longer, work longer: a synthesis report [electronic resource]. http://www.oecd.org/employment/employmentpoliciesanddata/ageingandemploy mentpolicies.htm.

Oeppen, J. and Vaupel, J. (2002). Broken limits to life expectancy. Science 296(5570): 1029-1031. doi:10.1126/science.1069675.

Quiggin, J. (2012). Zombie economics: how dead ideas still walk among us. Princeton, New Jersey: Princeton University Press.

Parr, N. (2006) Do children from small families do better? Journal of Population Research 23(1): 1-25. doi:10.1007/BF03031865. 
Parr, N. and Guest, R. (2011). The contribution of increases in family benefits to Australia's early $21^{\text {st }}$ century fertility increase: an empirical analysis. Demographic Research 25(6): 215-244. doi:10.4054/DemRes.2011.25.6.

Pigou, A.C. (1932). The economics of welfare. London: Macmillan.

Pollard, J.H. (1973). Mathematical models for the growth of human populations. London: Cambridge University Press.

Preston, S. (1975) The changing relation between mortality and level of economic development. Population Studies 29(2): 231-248. doi:10.2307/2173509.

Prettner, K. (2013). Population ageing and endogenous economic growth. Journal of Population Economics 26(2): 811-834. doi:10.1007/s00148-012-0441-9.

Prskawetz, A. and Sambt, J. (2014). Economic support ratios and the demographic dividend in Europe. Demographic Research 30(34): 963-1010. doi:10.4054/ DemRes.2014.30.34.

Ramsey, F.P. (1928). A mathematical theory of saving. Economic Journal 38(152): 543-559. doi:10.2307/2224098.

Rice, D.P. and Feldman, J.J. (1983). Living longer in the United States: demographic changes and health needs of the elderly. The Milbank Memorial Fund Quarterly, Health and Society 61(3): 362-396. doi:10.2307/3349863.

Rice, D.P. and Fineman, N. (2004). Economic implications of increased longevity in the United States. Annual Review of Public Health 25: 457-473. doi:10.1146/ annurev.publhealth.25.101802.123054.

Samuelson, P.A. (1958). An exact consumption--loan model of interest with or without the social contrivance of money. Journal of Political Economy 66(6): 467-482.

Sanchez-Romero, M. (2013). The Role of Demography on per Capita Output Growth and Saving Rates. Journal of Population Economics 26(4): 1347-1377. doi:10.1007/s00148-012-0447-3.

Scarborough, H. (2011). Intergenerational equity and the social discount rate. The Australian Journal of Agricultural and Resource Economics 55(2): 145-158. doi:10.1111/j.1467-8489.2011.00532.x.

Schmertmann, C.P. (1992). Immigrants' ages and the structure of stationary populations with below-replacement fertility. Demography 29(4): 595-612. doi:10.2307/ 2061854. 
Schmertmann, C.P. (2012). Stationary populations with below-replacement fertility. Demographic Research 26(14): 319-330. doi:10.4054/DemRes.2012.26.14.

Skirbekk, V. (2008). Age and productivity potential: a new approach based on ability levels and industry-wide task demand. Population and Development Review 34: 191-207.

Sobotka, T., Skirbekk, V., and Philipov, D. (2011). Economic recession and fertility in the developed world. Population and Development Review 37(2): 267-306. doi:10.1111/j.1728-4457.2011.00411.x.

Stern, N. (2007). The economics of climate change: the Stern review. Cambridge, UK: Cambridge University Press. doi:10.1017/CBO9780511817434.

Striessnig, E. and Lutz, W. (2012). Optimal fertility. Paper presented at the European Association of Population Studies Conferenc, Stockholm, Sweden, 13-16 June 2012.

Striessnig, E. and Lutz, W. (2014). How does education change the relationship between fertility and age dependency under environmental constraints? A longterm simulation exercise. Demographic Research 30(16): 465-492. doi:10.4054/ DemRes.2014.30.16.

United Nations Population Division, (UNPD) (2008). World population policies 2007. New York: United Nations.

Weil, D.N. (1999). Population growth, dependency and consumption. The American Economic Review 89(2): 251-255. doi:10.1257/aer.89.2.251.

Weitzman, M.L. (2007). Subjective expectations and asset-return puzzles. American Economic Review 97(4): 1102-1130. doi:10.1257/aer.97.4.1102.

Williamson, J.G. (2013). Demographic dividends revisited. Asian Development Review 30(2): 1-25. 


\section{Appendix A}

This appendix introduces a parameter capturing the social aversion to inequality in intertemporal living standards. A common ${ }^{59}$ functional form for $f\left(\frac{C}{N}\right)_{t}$ is $f\left(\frac{C}{N}\right)_{t}=\left(\frac{C}{N}\right)_{t}^{1-\beta}(1-\beta)^{-1}$, where $\beta$ measures the degree of social aversion to inequality in intertemporal living standards, also known as the elasticity of the marginal social valuation of living standards ${ }^{60}$. The simple case in the test assumed that $\beta \geq 0$. The larger $\beta$ is, the less society values higher per capita consumption. Suppose, for example, that in 50 years' time $\mathrm{C} / \mathrm{N}$ is expected to be twice that of today. Then a $\beta$ of 1 would imply that an increment in $C / N$ in 50 years has only half the social value of the same increment today, while a $\beta$ of 2 would imply that the same increment in $C / \mathrm{N}$ would have only a quarter the social value of the same increment today ${ }^{61}$. Hence $\beta$ measures the degree of social aversion to intergenerational inequality in $C / N$ that occurs over time due to labour productivity growth.

This implies the following objective function:

$$
\begin{aligned}
V & =(1-\beta)^{-1}\left(\frac{C}{L}\right)_{0}^{1-\beta}\left[\sum_{t=0}^{\infty} \frac{\left(1+g_{A}\right)^{t(1-\beta)}}{(1+\rho)^{t}}\left(\frac{L^{\alpha}}{N}\right)_{t}^{1-\beta}\right] \\
& =(1-\beta)^{-1}\left(\frac{C}{L}\right)_{0}^{1-\beta}\left[\sum_{t=0}^{\infty}\left(\frac{L^{\alpha}}{N}\right)_{t}^{1-\beta}(1+\theta)^{t}\right]
\end{aligned}
$$

${ }^{59}$ See, for example, the seminal paper on the economics of ageing populations, Cutler et al. (1990).

${ }^{60}$ To see this, note that $f^{\prime}\left(\frac{C}{N}\right)_{t}=\left(\frac{C}{N}\right)_{t}^{-\beta}$, hence $\frac{d\left[\ln \left(f^{\prime}\left(\frac{C}{N}\right)_{t}\right)\right]}{d\left[\ln \left(\frac{C}{N}\right)_{t}\right]}=-\beta$ where $\beta \geq 0$. The value of $\beta$ reflects the notion that a unit of additional consumption becomes less valuable the greater the total level of consumption. Note that this is different to the rate at which the social valuation of a unit of living standards at time $t$ declines, which is simply the social discount rate.

${ }^{61}$ The marginal social valuation of $C / N$ at $t$ is $(C / N)_{t}^{-\beta}$ and at $t+50$ is $\left[2(C / N)_{t}\right]^{-\beta}$. 
where $(1+\theta)^{t}=\frac{\left(1+g_{A}\right)^{t(1-\beta)}}{(1+\rho)^{t}}$.

From (A1), the social evaluation of alternative paths for living standards depends on the path of $(L / N)_{t}$ and the factor $(1+\theta)^{t}$ which grows over time at the (approximate $\left.^{62}\right)$ rate $\theta=g_{A}-\left(\rho+\beta g_{A}\right)$. The term $\left(\rho+\beta g_{A}\right)$ is a consumption discount rate which is the rate at which consumption per capita $(C / N)$ is discounted in determining its social value. The consumption discount rate consists of two discount parameters: the pure social rate of time preference, $\rho$, and $\beta$. Hence both parameters $\beta$ and $\rho$ discount $C / N$ over time, $\rho$ explicitly and $\beta$ implicitly. Parameter $\rho$ discounts $C_{t} / N_{t}$ according to the distance of $\mathrm{t}$ in the future, and $\beta$ discounts $C_{t} / N_{t}$ according to the size of $C_{t} / N_{t}$ which implies a time discount of $\mathrm{C}_{\mathrm{t}} / \mathrm{N}_{\mathrm{t}}$ in that $\mathrm{C}_{\mathrm{t}} / \mathrm{N}_{\mathrm{t}}$ grows over time at the rate $g_{A}$ (by assumption).

The consumption discount rate plays an important role in neoclassical models of optimal economic growth, such as those noted in the text. The philosophical/ethical issues in the choice of $\rho$ were also mentioned. Similar issues in the choice of $\beta$ are debated in the literature. Empirical evidence based on 20 OECD countries in Evans (2005) suggests a value for $\beta$ of 1.4. Nordhaus (2007) argues that because both $\rho$ and $\beta$ discount future consumption the choice of values for these parameters should be considered jointly for any given value of $g_{A}$. To put it another way, a given consumption discount rate can be achieved with a wide range of combinations of plausible values of $\rho$ and $\beta$. The combination of $\rho$ and $\beta$ was 0.0175 and zero, respectively, giving a value of $\theta$ of -0.0025 . The same value of $\theta$ is achieved with an alternative $\beta$ of 1.0 and $\rho$ of 0.0025 (given $g_{A}=0.015$ ). This would yield the same value of $V$ given the same demographic path. Hence, for sensitivity, alternative combinations of $\beta$ and $\rho$ are chosen, implying alternative values of $\theta$ (Table A1).

Table A1: Alternative combinations of $\rho, \beta$ and $\theta$ (given $g=0.015$ )

\begin{tabular}{llll}
\hline & $\boldsymbol{\rho}$ & $\boldsymbol{\beta}$ & $\boldsymbol{\theta}$ \\
\hline Base & 0.0175 & 0 & -0.0025 \\
Sim 1 & 0.005 & 1 & -0.005 \\
Sim 2 & 0.004 & 1.4 & -0.01 \\
Sim 3 & 0.005 & 2.0 & -0.02 \\
\hline
\end{tabular}

${ }^{62}$ Taking the natural logarithm and differentiating with respect to $t$. 


\section{Appendix B}

This section presents formulae which extend the proposed valuation method to allow for differing linear effects of the proportionate age distribution, firstly on average labour productivity $\left(Y_{t} / L_{t}\right)$ and secondly on consumption share of GDP $\left(C_{t} / Y_{t}\right)$.

Extension to differential (linear) effects of age groups on labour productivity $(Y / L)$

Equation (4) may be extended to allow for departures of the growth of average labour productivity $\left(Y_{t} / L_{t}\right)$ from the geometric growth pattern, which are linked to differential effects of the proportions of the employed in the different age ranges.

$$
\left(\frac{C_{t}}{N_{t}}\right)=\left(\frac{C_{0}}{Y_{0}}\right) A_{0}\left(1+g_{A}\right)^{t} \frac{\left(\sum_{x} \gamma_{x} H_{x, t}\right)^{\alpha}}{N_{t}}
$$

where $\gamma_{x}$ are coefficients indicating the differing effects (weights) of hours worked by people of different ages on total productivity (Skirbekk 2008). The valuation components are calculated by replacing $\left(L^{\alpha}{ }_{t} / N_{t}\right)$ by $L^{* \alpha}{ }_{t} / N_{t}=\frac{\left(\sum_{x} \gamma_{x} H_{x, t}\right)^{\alpha}}{N_{t}}$ and

$$
\begin{gathered}
\left(L_{s, t}^{\alpha}{ }_{s, t} N_{s, t} \text { by }\left(\mathrm{L}_{\mathrm{s}, t}^{* \alpha} / \mathrm{N}_{\mathrm{s}, t}\right)=\left(\frac{\left(\sum_{x} \gamma_{x} H_{x, t}\right)^{\alpha}}{N_{s, t}}\right)\right. \text { in (8) and (9). Thus } \\
V=\left(\frac{C_{0}}{Y_{0}}\right) A_{0}\left(\sum_{t=0}^{\infty}\left(\frac{\left(1+g_{A}\right)^{t}}{(1+\rho)^{t}}\left(\frac{L_{s, t}^{* \alpha}}{N_{s, t}}\right)\right)\right. \\
\left.+\sum_{t=0}^{\infty} \frac{\left(1+g_{A}\right)^{t}}{(1+\rho)^{t}}\left(\left(\frac{L_{t}^{* \alpha}}{N_{t}}\right)-\left(\frac{L_{s, t}^{* \alpha}}{N_{s, t}}\right)\right)\right)
\end{gathered}
$$

Further extensions in which departures of the growth of average labour productivity from the geometric growth pattern are modelled as functions of future capital-to-labour ratios, where future capital is in turn a function of the projected population age structure, are also feasible. 
Extension to differential (linear) effects of age groups on consumption share of GDP $(C / Y)$

The case where differential (linear) effects of age groups on consumption share of GDP $(C / Y)$ (and where there are no effects on population age structure on the course of average labour productivity change) has a parallel formulation to the above, replacing $\left(\mathrm{C}_{t} / Y_{t}\right)$ by a weighted average for the population $\left(C_{t} / Y_{t}\right)=\left(\sum_{x}\left(\eta_{x} \times N_{t}\right)\right) / N_{t}$ in (4) and, additionally, $\left(C_{s, t} / Y_{s, t}\right)$ by $\left(C_{s, t}{ }^{*} / Y_{s, t}\right)=\left(\sum_{x}\left(\eta_{x} \times N_{x, s}\right)\right) / N_{s, t}$, in (8), where the $\eta_{\mathrm{x}}$ are coefficients indicating the differing effects of people of different ages on the consumption share of GDP. 
Parr \& Guest: A method for socially evaluating the effects of long run demographic paths on living standards 